\title{
Hypothermic treatment after computer-controlled compression in minipig: A preliminary report on the effect of epidural vs. direct spinal cord cooling
}

\author{
MONIKA ZAVODSKA ${ }^{1}$, JAN GALIK ${ }^{1}$, MARTIN MARSALA ${ }^{1,2}$, STEFANIA PAPCUNOVA ${ }^{1}$, \\ JAROSLAV PAVEL ${ }^{1}$, ENIKO RACEKOVA ${ }^{1}$, MARCELA MARTONCIKOVA ${ }^{1}$, IGOR SULLA ${ }^{1,3}$, \\ MIROSLAV GAJDOS ${ }^{4}$, IMRICH LUKAC ${ }^{4}$, JOZEF KAFKA ${ }^{4}$, VALENT LEDECKY ${ }^{5}$, IGOR SULLA JR. ${ }^{5}$, \\ PETER REICHEL $^{5}$, ALEXANDRA TRBOLOVA ${ }^{5}$, IGOR CAPIK ${ }^{5}$, KATARINA BIMBOVA ${ }^{1}$, MARIA BACOVA ${ }^{1}$, \\ ANDREA STROPKOVSKA ${ }^{1}$, ALEXANDRA KISUCKA ${ }^{1}$, DANA MIKLISOVA ${ }^{6}$ and NADEZDA LUKACOVA ${ }^{1}$ \\ ${ }^{1}$ Institute of Neurobiology, Biomedical Research Center, Slovak Academy of Sciences, 04001 Košice, Slovakia; \\ ${ }^{2}$ Department of Anesthesiology, Neuroregeneration Laboratory, University of California-San Diego, San Diego, CA 92093, \\ USA; ${ }^{3}$ Hospital of Slovak Railways, 04001 Košice; ${ }^{4}$ Department of Neurosurgery, Faculty of Medicine, \\ University of Pavol Jozef Safarik, 04066 Košice; ${ }^{5}$ Department of Small Animal Clinic, University of \\ Veterinary Medicine and Pharmacy, 04181 Košice; ${ }^{6}$ Department of Vector-borne Diseases, \\ Institute of Parasitology, Slovak Academy of Sciences, 04001 Košice, Slovakia
}

Received March 5, 2017; Accepted June 29, 2018

DOI: $10.3892 / \mathrm{etm} .2018 .6831$

\begin{abstract}
The aim of the present study was to investigate the therapeutic efficacy of local hypothermia (beginning 30 min post-injury persisting for $5 \mathrm{~h}$ ) on tissue preservation along the rostro-caudal axis of the spinal cord $(3 \mathrm{~cm}$ cranially and caudally from the lesion site), and the prevention of injury-induced functional loss in a newly developed computer-controlled compression model in minipig (force of impact $18 \mathrm{~N}$ at $\mathrm{L} 3$ level), which mimics severe spinal cord injury (SCI). Minipigs underwent SCI with two post-injury modifications (durotomy vs. intact dura mater) followed by hypothermia through a perfusion chamber with cold (epidural $\mathrm{t} \approx 15^{\circ} \mathrm{C}$ ) saline, DMEM/F12 or enriched DMEM/F12 (SCI/durotomy group) and with room temperature $\left(\mathrm{t} \approx 24^{\circ} \mathrm{C}\right)$ saline (SCI-only group). Minipigs treated with post-SCI durotomy demonstrated slower development of spontaneous neurological improvement at the early postinjury time points, although the outcome at 9 weeks of survival did not differ significantly between the two SCI groups. Hypothermia with saline $\left(\mathrm{t} \approx 15^{\circ} \mathrm{C}\right)$ applied after SCI-durotomy improved
\end{abstract}

Correspondence to: Dr Nadezda Lukacova or Dr Jan Galik, Institute of Neurobiology, Biomedical Research Center, Slovak Academy of Sciences, Soltesovej 4-6, 04001 Košice, Slovakia E-mail: lukacova@saske.sk

E-mail: galik@saske.sk

Key words: spinal cord, local hypothermia, neurofilaments, motoneurons, white matter integrity, durotomy white matter integrity in the dorsal and lateral columns in almost all rostro-caudal segments, whereas treatment with medium/enriched medium affected white matter integrity only in the rostral segments. Furthermore, regeneration of neurofilaments in the spinal cord after SCI-durotomy and hypothermic treatments indicated an important role of local saline hypothermia in the functional outcome. Although saline hypothermia $\left(24^{\circ} \mathrm{C}\right)$ in the SCI-only group exhibited a profound histological outcome (regarding the gray and white matter integrity and the number of motoneurons) and neurofilament protection in general, none of the tested treatments resulted in significant improvement of neurological status. The findings suggest that clinically-proven medical treatments for SCI combined with early 5 h-long saline hypothermia treatment without opening the dural sac could be more beneficial for tissue preservation and neurological outcome compared with hypothermia applied after durotomy.

\section{Introduction}

Spinal cord injury (SCI) is associated with severe and long-lasting neurological dysfunction in humans. Currently, there is no effective treatment to reverse the consequences resulting from traumatic SCI. While in experimental studies, various pharmacological agents and therapeutic approaches have tended to improve outcomes in animal SCI models (1), unfortunately none of these therapies has been successfully transferred into clinical practice.

After SCI the development of the lesion consists of primary and secondary phases $(2,3)$. The primary phase is the direct mechanical injury to the spinal cord tissues itself, which is followed by a secondary phase leading to a marked enlargement of the primary lesion within several h after SCI. This 
slow evolution of the lesion has been referred to as progressive hemorrhagic necrosis or 'autodestruction' $(4,5)$. It results in secondary loss of vital spinal cord tissue and, in some species including humans, leads to formation of a cystic cavity surrounded by glial scar tissue.

From the clinical point of view, the secondary phase is very important because it represents the target for therapeutic interventions which could minimize the extent of the final lesion (6). To this date the treatments options for SCI are limited to surgical interventions, early steroid administration and physical therapy. These therapeutic interventions are effective only under specific circumstances $(7,8)$, and their effect on the final outcome is modest at best.

One potential treatment which has shown promising results over the past few decades is therapeutic hypothermia. Although the entire range of the effects of hypothermia is not fully understood, a few observations are notable (9-12). Hypothermia seems to work through several mechanisms which start to operate soon after trauma and may have an important role in the functional outcome. Neuroprotective effects of systemic and regional hypothermia have been described $(9-11,13,14)$. It has been demonstrated that hypothermia has a powerful effect on control of the injury-induced immune response (15), apoptosis and inflammation (13,14,16-22). Hypothermia also delays glutathione release, reduces oxidative stress and increases spinal cord tolerance to ischemia (23-26). There are also numerous articles illustrating the neuroprotective effect of hypothermia on neural stem cell differentiation and survival $(15,27-35)$.

The published studies have defined the most effective target temperature range for systemic hypothermia (36-39) and they suggest that the most effective cooling is such that i) is initiated early after injury, ii) lasts for long periods (up to 48 -h) and iii) is followed by slow rewarming $(13,38)$.

Relatively little experimental data are available for local hypothermia. In general, the results indicate that longer durations of local hypothermia (at least $48 \mathrm{~h}$ ) yield better results than shorter durations (14,40-43). However, there are studies indicating that duration of hypothermia $<48 \mathrm{~h}$ may be sufficient. In the literature, some animal studies found that local hypothermia improved outcomes after SCI $(37,38,42,44-50)$, whereas others concluded that it has no effect (51-54). Interestingly, in a clinical study by Hansebout and Hansebout (55), positive results were observed with local hypothermia lasting $<4 \mathrm{~h}$. In this study, the cooling was initiated $7.1 \mathrm{~h}$ after injury, the mean duration of the treatment was $3.7 \mathrm{~h}$ and there was an uncontrolled rewarming rate.

In the present study, we wanted to test the protective effect of local hypothermia after precisely-controlled SCI model in minipigs $(56,57)$ representing a preclinical model which mimics human patients more closely than the widely-used rodent models. In a series of experiments, we modified i) the cooling approach (durotomy vs. intact dura mater), ii) the kind of cooling solutions (saline, medium or enriched medium), and iii) the degree of hypothermia $\left(15\right.$ or $24^{\circ} \mathrm{C}$ just above the $\mathrm{SCI}$ ). The outcome parameters involved long-term behavioral testing for the recovery of neurological functions, and detailed histological analyses of the spinal cord lesions involving axonal quantification using a selective marker of mature axons (SMI-312).

\section{Materials and methods}

Animals. A total of 24 adult female Göttingen-Minnesota -Liběchov minipigs each weighing $25-35 \mathrm{~kg}$ were used in this study. The animals were maintained in standard conditions with ad libitum access to food and water. The experimental protocols were prepared in accordance with the EC Council Directive (2010/63/EU) regarding the use of animals in research and approved by the State Veterinary and Food Administration of the Slovak Republic (decision no. 1319/13-221) as well as by the Ethical Commission of the University of Veterinary Medicine and Pharmacy (Kosice, Slovak Republic). All efforts were made to minimize the size of experimental groups and animal suffering.

Experimental groups. Two sets of experiments with modifications in post-injury approach (durotomy vs. intact dura mater) and temperature of perfusion solutions $\left(15\right.$ or $\left.24^{\circ} \mathrm{C}\right)$ were carried out.

The animals in Experiment 1 were divided into the following groups: i) naïve control-without anesthesia or surgical intervention ( $\mathrm{n}=3)$; ii) SCI at L3 level + durotomy ( $5 \mathrm{~h}$ ) and survival for 9 weeks ( $\mathrm{n}=3)$; iii) SCI at L3 level + durotomy followed by $4^{\circ} \mathrm{C}$ saline treatment (target temperature: $15^{\circ} \mathrm{C}$ for $5 \mathrm{~h}$ ) and survival for 9 weeks $(n=3)$; iv) SCI at L3 level + durotomy followed by $4^{\circ} \mathrm{C}$ medium treatment (target temperature, $15^{\circ} \mathrm{C}$ for $5 \mathrm{~h}$ ) and survival for 9 weeks $(n=3)$; v) SCI at L3 level + durotomy followed by enriched $4{ }^{\circ} \mathrm{C}$ medium treatment (target temperature: $15^{\circ} \mathrm{C}$ for $5 \mathrm{~h}$ ) and survival for 9 weeks $(\mathrm{n}=3)$.

In order to relieve the edema and provide direct contact of cooling solutions with the spinal cord, the minipigs underwent durotomy immediately after SCI. Medium (DMEM/F12) was composed of rh Transferrin $100 \mathrm{mg} / \mathrm{l}$, rh Insulin $25 \mathrm{mg} / 1$, Glucose $1.56 \mathrm{~g} / \mathrm{l}$, Progesterone $6.3 \mu \mathrm{g} / \mathrm{l}$, Putrescine $16.1 \mathrm{mg} / \mathrm{l}$, Selenium $5.2 \mu \mathrm{g} / \mathrm{l}$. Enriched medium was composed of DMEM/F12 + rh bFGF $10 \mu \mathrm{g} / \mathrm{l}$, rh BDNF $10 \mu \mathrm{g} / 1$, rh GDNF $10 \mu \mathrm{g} / \mathrm{l}$, rh VEGF $10 \mu \mathrm{g} / \mathrm{l}$, Creatine $20 \mathrm{mM}$. The treatments were initiated $30 \mathrm{~min}$ after SCI and durotomy, and maintained for $5 \mathrm{~h}$ (see details of hypothermic treatment below).

The animals in Experiment 2 were divided into the following groups: i) naïve control-without anesthesia or surgical intervention $(n=3)$; ii) SCI at L3 level (intact dura mater) and survival for 9 weeks $(\mathrm{n}=3)$; iii) SCI at L3 level (intact dura mater) followed by room temperature saline treatment (target temperature: $24^{\circ} \mathrm{C}$ for $\left.5 \mathrm{~h}\right)$ and survival for 9 weeks $(\mathrm{n}=3)$. The treatment was initiated $30 \mathrm{~min}$ after SCI and maintained for $5 \mathrm{~h}$ (see details of hypothermic treatment below).

Pre-contusion procedures. Three days before the surgery, the animals were pre-treated with a combination of penicillin and streptomycin, administered intramuscularly in a dose of $0.5 \mathrm{ml} / 30 \mathrm{~kg}$ (Norbrook Laboratories, Newry, Northern Ireland). The minipigs were premedicated $30 \mathrm{~min}$ before surgical procedure with an intramuscular injection of Stresnil (2 mg/kg; Janssen Pharmaceutica, Beerse, Belgium) and Atropin $(0.5 \mathrm{mg} / \mathrm{kg}$; Biotika, Slovenská Lupča, Slovakia). Anesthesia was induced by intravenous administration of Thiopental (10 mg/kg; Czech Pharma, Czech Republic) 
A
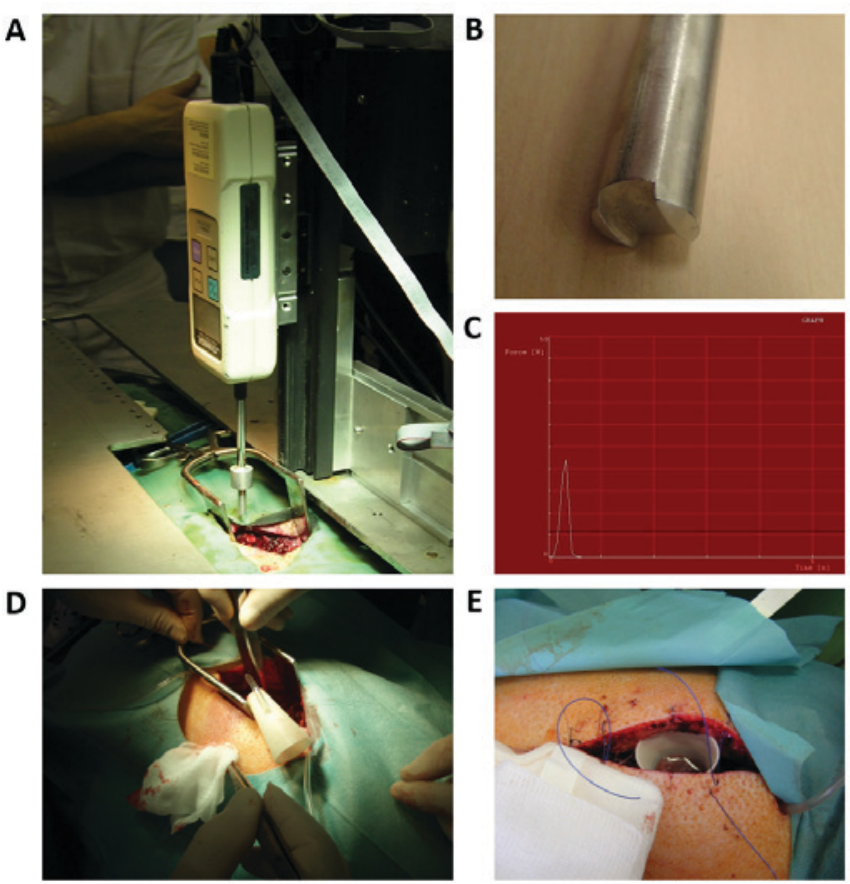

Figure 1. (A) Computer-controlled apparatus for induction of contusive SCI (B) Stainless steel rod with $5 \mathrm{~mm}$ diameter causing SCI when it impacts on the spinal cord. (C) Real impact force recorded during SCI. (D and E) Perfusion chamber implanted above the epicenter of SCI for inducing local hypothermia. SCI, spinal cord injury.

followed by identification of the precise location of the L3 vertebra using plain X-rays in a lateral projection (58). Afterwards, the animals were endotracheally intubated (diameter, 5.0-6.0 $\mathrm{mm}$ ) and anesthesia was maintained by inhalation of $1.5 \%$ Sevofluran (Baxter, Prague, Czech Republic) mixed with oxygen. Analgesia was supported by administration of Butomidor $(0.4 \mathrm{mg} / \mathrm{kg}$, i.v.; Richter Pharma, Austria). Catheters for the administration of infusions and medications were inserted bilaterally into the cephalic and auricular veins. Standard monitoring of life-function indicators (mainly heart rate, respiratory rate, blood pressure and oxygen saturation) was performed during the whole surgical procedure and hypothermic treatment. Hydration was maintained with lactated Ringer's solution.

Spinal cord contusion. The animals were placed into a special immobilization apparatus (Fig. 1A). After disinfection of the lumbar area, a midline skin and subcutaneous fat incision was performed from L2 to L4 segments. Muscles were dissected from the spinous processes and vertebral arches and retracted, then a dorsal laminectomy at the L3 segment was performed. Afterwards the minipigs received the muscle relaxant sukcinylcholine and SCI was accomplished using a computer-operated compression device (Fig. 1A) consisting of a stepping motor (ViDiTo, Kosice, Slovakia) and a digital force gauge connected to a 5-mm diameter circular aluminum bar (Fig. 1B). Parameters for SCI (velocity: $10 \mathrm{~mm} / \mathrm{sec}$; force: $18 \mathrm{~N}$ ) were preset by the computer software (56). To control the uniformity of the impact force, the contusion curve was recorded in each animal (Fig. 1C). The force impact was uniform without significant differences between animals or groups. The real peak force in Experiment 1 was $21.08 \mathrm{~N} \pm 0.79$ and in Experiment 2 it was $20.72 \mathrm{~N} \pm 0.97$. After SCI, the paraspinal musculature and skin were sutured with several absorbable stitches or durotomy and subsequent hypothermic treatments were performed depending on the experimental group. The animals were housed in threesomes to recover. Post-operative care included bladder expression twice a day, antibiotic administration Penstrepten $(0.5 \mathrm{ml} / 30 \mathrm{~kg} / \mathrm{day}$; Biotika) for 10 days, cleaning the hind limbs and monitoring of skin irritation and development of decubitus ulcers.

Implantation of perfusion chamber. In the case of animals undergoing experimental treatment, the perfusion chamber was implanted over the exposed spinal dural sac containing the spinal cord immediately after performing the SCI (Fig. 1D and E). A cone-shaped chamber with both ends opened was made from ABS plastic using a uPrint SE 3D printer (Stratasys, Eden Prairie, MN, USA). It had ellipse-shaped openings, the lower opening measuring 20x14 mm and the upper one $40 \times 30 \mathrm{~mm}$; the height of the chamber was $50 \mathrm{~mm}$. The chamber was fitted with two tubings (inflow and outflow). The smaller opening of the chamber was about the size of the laminectomy, so it could be freely placed directly on the dura mater without any fixation to the spine or paravertebral muscles. Two superficially-placed stitches were used to partially close the wound, making the skin edges slightly embracing the chamber.

Hypothermia. Hypothermia with cold solutions was carried out locally with the help of the perfusion chamber. The inflow tubing was connected to the tank with sterile cold perfusion solution. The cooling of the injury site was initiated $30 \mathrm{~min}$ after SCI or SCI + durotomy. At the beginning, the solution drip rate was manually adapted to ensure that the temperature of fluid in the perfusion chamber (just above the SCI) was maintained at $15^{\circ} \mathrm{C}$ in Experiment 1 or at $24^{\circ} \mathrm{C}$ in Experiment 2. Given that cooling was applied locally, the temperature of the solution in the chamber decreased to $15^{\circ} \mathrm{C}$ or $24^{\circ} \mathrm{C}$ very rapidly, max. within 5-6 $\mathrm{min}$ and was measured at $30 \mathrm{~min}$ intervals using a needle-tip thermometer (Omega Bio-Tek, Inc., Norcross, GA, USA) during the whole treatment procedure. Hypothermic treatment of the injured spinal cord lasted for $5 \mathrm{~h}$. Continuous inflow of the perfusion solution into the chamber was regulated by a peristaltic pump (bubble rise distance, flow $2 \mathrm{ml} / \mathrm{min}$; Heidolph, Schwabach, Germany). The outflow tubing was used to drain excess perfusion solution. The average temperature of cooling solutions in the chamber (just above the site of injury) was $15.43^{\circ} \mathrm{C} \pm 3.75$ in Experiment 1 and $24.06^{\circ} \mathrm{C} \pm 1.95$ in Experiment 2. There were no significant differences in epidural temperature between groups during the whole treatment period. After the therapy, the perfusion chamber was extracted, the dura mater in Experiment 1 was closed with absorbable sutures, and the wound was sutured in layers. These animals were housed in separated cages to recover.

To minimize variability in body temperature and to prevent systemic hypothermia during treatment the minipigs were covered with an isothermal foil. The rectal temperature of each animal was measured at 30 min intervals. When the body temperature dropped below $36^{\circ} \mathrm{C}$, the animals were heated with a stream of warm air blown below the blanket covering the animal. The average rectal temperature was $36.47^{\circ} \mathrm{C} \pm 0.70$ 
in Experiment $1,36.02^{\circ} \mathrm{C} \pm 0.87$ in the SCI group, and $36.10^{\circ} \mathrm{C} \pm 0.59$ in the saline group in Experiment 2. No significant differences were recorded in rectal temperatures between groups during the treatment period.

Behavioral assessment. Three weeks before the surgery each minipig underwent half an hour of training for 5 days/week to walk upon command, up and down a rubber mat (width, $0.8 \mathrm{~m}$; length, $5.2 \mathrm{~m})$. Post-operative neurological impairment was tested using a 21-point scale, ranging from complete paraplegia (zero) to normal ambulation (20 points) (57). The scoring points took into consideration the hind-limb movement for each individual joint, the capability of each animal to get up by itself, its trunk stability and stepping coordination. The scoring points represent the sequential recovery stages which the minipigs attained after SCI. Porcine neurological motor scores (1-8) represent slight or extensive movement for each individual joint of the hind limbs. Points (9-11) represent sweeping and the ability to get up by itself (with or without assistance; the animals were not necessarily able to maintain balance), and points $(12-20)$ characterize the ability to walk from a few steps without fore-limb/hind-limb coordination to consistent plantar-hoof stepping and consistent fore-limb/hind-limb coordination. The neurological impairment was tested under blinded outcome assessment weekly for nine weeks of survival. Each minipig was allowed to walk freely on the rubber mat for $10 \mathrm{~min}$ without assistance. A video recording was made of each evaluation. In order to reduce bias, three independent observers were involved to determine the neurological scale. The inter-rater differences in the scores varied by one point at most. The discrepancies between the raters were discussed and clarified.

Spinal cord tissue preparation. At the end of the experiment, the animals were anesthetized by intravenous administration of Thiopental (10 mg/kg; Czech Pharma) and transcardially perfused with heparinized saline (5l) followed by $4 \%$ paraformaldehyde in $0.1 \mathrm{M}$ phosphate-buffered saline (PBS; pH 7.4, 5l). The lumbar spinal cords encompassing the injury site were carefully dissected out, cleaned of the dura mater remnants and post-fixed in $4 \%$ paraformaldehyde overnight. Next day, the spinal cords were cut into seven $1 \mathrm{~cm}$ segments: cranial $(+3,+2,+1)$, central $(0)$ and caudal $(-1,-2,-3)$ segments. The spinal cord segments were cryoprotected in a solution of $30 \%$ sucrose in PBS at $4^{\circ} \mathrm{C}$ for 2 days, cut into transverse serial sections $(30 \mu \mathrm{m})$ on a cryostat (Leica Microsystems, Wetzlar, Germany) and used for histological and immunohistochemical analyses.

Histology. The selected sections were placed in PBS for $10 \mathrm{~min}$, in $70 \%$ alcohol for $2 \mathrm{~h}$ and overnight in $0.1 \%$ Luxol fast blue (LFB) at room temperature. Next day, the sections were rinsed in distilled water and PBS for 3 min, put into $0.05 \%$ aqueous lithium carbonate followed by $40 \%$ alcohol, PBS and distilled water. Afterwards, the slices were counterstained with $0.2 \%$ cresyl violet for $4 \mathrm{~min}$ and rinsed in distilled water. Finally, the sections were dehydrated through a graded series of ethanol and xylene and covered with coverslips. Sections were visualized using an Olympus BX51/BX52 light microscope (magnification $\times 5$, fitted with an Olympus DP50 digital

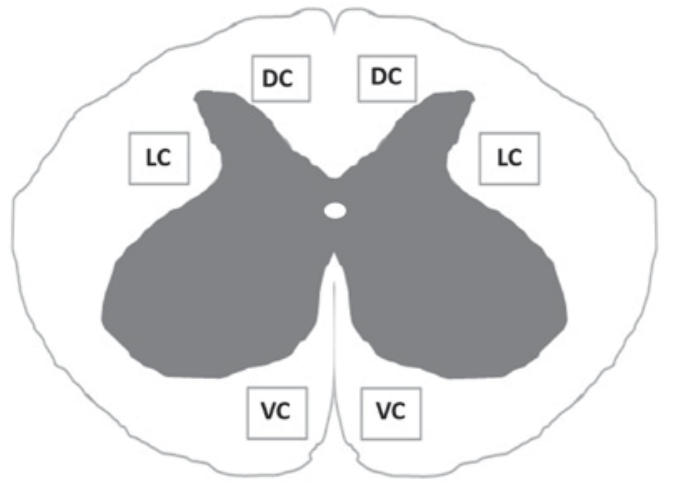

Figure 2. Schematic illustration of regions of interest. The number of neurofilaments was quantified in the DC, LC and VC. Measuring frame size in each area was 800x600 $\mu \mathrm{m}$. DC, dorsal columns; LC, lateral columns; VC, ventral columns.

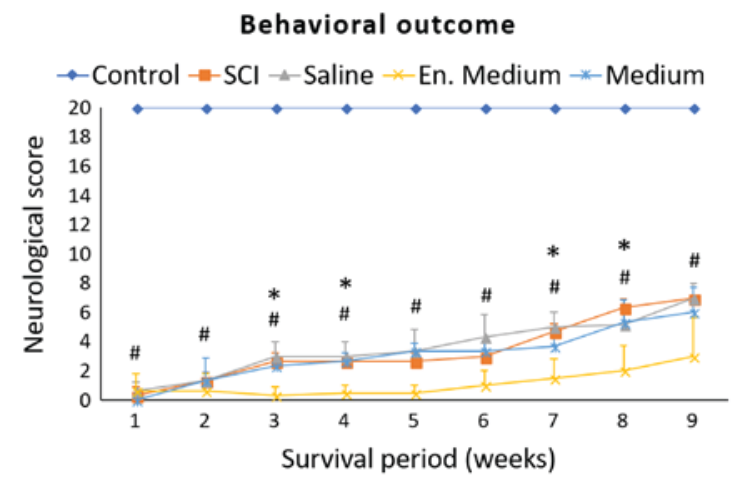

Figure 3. Experiment 1. Behavioral recovery of animals during 9-week survival after SCI and subsequent hypothermia with cold saline, en. medium or medium. The scoring points range from complete paraplegia (point zero) to normal hindlimb function (point 20). Data are the mean values \pm standard deviation. The results were statistically evaluated for each week separately using one-way analysis of variance followed by Sidak's multiple comparison test. ${ }^{\#} \mathrm{P}<0.0001$, control vs. SCI; ${ }^{*} \mathrm{P}<0.05$, SCI vs. hypothermia with en. medium. SCI, spinal cord injury; en. medium, enriched medium.

camera coupled with a computer equipped with Olympus DP Image software, version 3.1; Olympus Corporation, Tokyo, Japan). Slices from each segment were evaluated. The areas of spared white and grey matter were measured using Image J 1.44 (National Institutes of Health, Bethesda, MD, USA), expressed as a percentage and compared to control (control values were expressed as 100\%). The cresyl violet counterstain enabled motor neurons to be counted. Motor neurons located in the ventral horn $(\mathrm{VH})$ with clearly visible nuclei on both sides of the spinal cord were counted.

Immunohistochemistry. Selected slides taken from each rostral and caudal segment (except for the epicenter of the injury) were pre-treated in PBS for $3 \times 10$ min and incubated in blocking solution consisting of 5\% normal goat serum in $0.1 \mathrm{M}$ PBS with $0.3 \%$ Triton-X 100 (normal goat serum; Vector Laboratories, Burlingame, CA, USA) for $2 \mathrm{~h}$ at room temperature. Afterwards, the slices were incubated overnight at $4^{\circ} \mathrm{C}$ with mouse monoclonal anti-neurofilament primary antibody (Pan-Axonal Neurofilament Marker SMI-312; dilution, 1:1,000; Abcam, Cambridge, UK) for $24 \mathrm{~h}$ at $4^{\circ} \mathrm{C}$. In the next step, the sections were rinsed 3 times in PBS, 
A

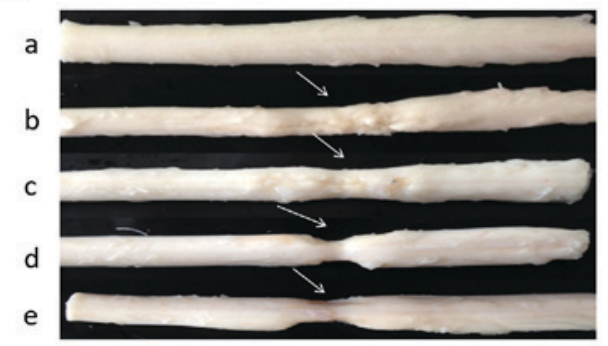

C

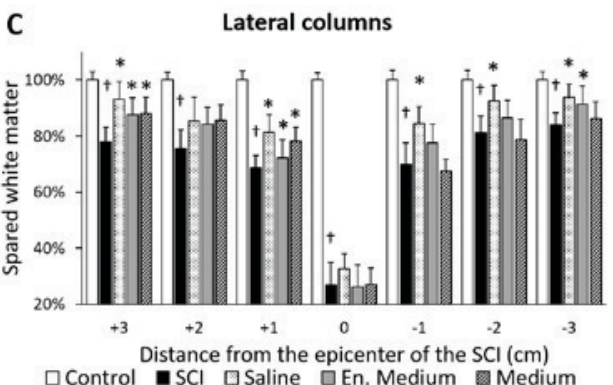

B

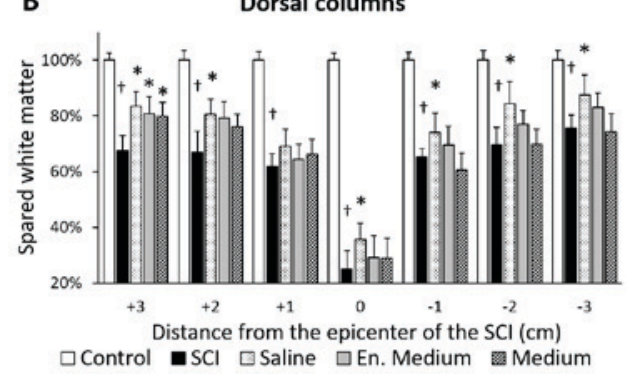

D

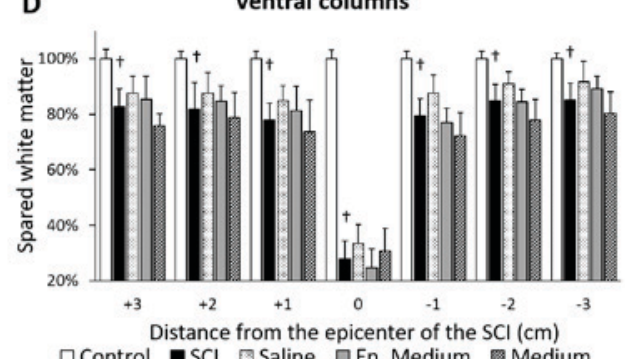

Figure 4. Experiment 1. (A) Macroscopic images of spinal cord and white matter sparing in spinal cord columns after SCI and hypothermic treatments. Spinal cords of animals in the (Aa) control, (Ab) 9 weeks after SCI, (Ac) after subsequent hypothermia with cold saline, (Ad) enriched medium, or (Ae) medium were indicated. Arrows demonstrated the epicenter of injury. White matter sparing after SCI and hypothermic treatment in (B) dorsal, (C) lateral and (D) ventral columns. Data are the mean values \pm standard deviation. Ordinary one-way analysis of variance followed by Sidak's multiple comparison test was used for the assessment of differences between experimental groups in each segment separately. ${ }^{\dagger}<0.0001$, vs. Control; ${ }^{*} \mathrm{P}<0.05$ vs. SCI. SCI, spinal cord injury; en. medium, enriched medium.

followed by incubation in secondary anti-mouse antibody (RhodamineRed; dilution, 1:200; Invitrogen; Thermo Fisher Scientific, Inc., Waltham, MA, USA) for $90 \mathrm{~min}$ at room temperature. Sections were rinsed in PBS 3x10 min, mounted with Fluoromount (Serva, Heideberg, Germany) and covered with coverslips. SMI-312 positive axons were counted by an observer in a blinded procedure using a x20 lens over an area of $800 \times 600 \mu \mathrm{m}$ in three specific regions of the white matter: dorsal, lateral and ventral columns (DC, LC, VC) (Fig. 2), using Image J graphics software (ImageJ 1.44; National Institutes of Health). The images were converted into a binary image using a set threshold. NF positive axons were counted automatically using the 'analyze particles' tool $(57,59)$. The number of neurofilaments (expressed as percentage of $\mathrm{NF} / \mathrm{mm}^{2}$ ) was evaluated bilaterally from ten randomly-selected transverse slices of each spinal cord section. In the control group the number of neurofilaments was expressed as $100 \%$.

Statistical analysis. GraphPad Prism 6 software (GraphPad Software, Inc., La Jolla, CA, USA) was used for the statistical analyses. The differences in behavioral outcomes between individual groups were assessed using ordinary one-way ANOVA followed by Sidak's multiple comparisons test with statistical significance set at $\mathrm{P}<0.05$ for each week separately. The data collected from the white and grey matter sparing, number of motoneurons and number of neurofilaments were also subjected to ordinary one-way ANOVA followed by Sidak's multiple comparison test; each spinal cord segment was assessed separately. The unpaired Student t-test was used to determine the effect of durotomy. The comparison between SCI group from Experiment 1 and SCI group from Experiment 2 was performed and $\mathrm{P}<0.05$ was considered to indicate a statistically significant difference. Spearman's correlation analysis was used to establish the relationship between spinal cord tissue integrity and the neurological outcome of the animals. The data from all 24 animals from both experiments were utilized. All data are presented as mean \pm standard deviation.

\section{Results}

\section{Experiment 1: Spinal cord exposed by durotomy}

Behavioral assessment. Neurological outcomes of minipigs recorded during a 9-weeks survival period are summarized in Fig. 3. All animals displayed complete paraplegia immediately after SCI. In the SCI group, one week after SCI, two animals suffered from complete paraplegia and one was capable of slight movement in one hip joint (ANOVA summary for 1st week: $\mathrm{F}(4,10)=575.8 ; \mathrm{P}<0.0001$; Control vs. SCI $\mathrm{P}<0.0001)$. During the whole survival period, the animals slowly recovered some of their hind-limb functions characterized by slight movement in all three joints. The outcome improved gradually and at the end of the survival period their motor score reached $7 \pm 0.0$ (ANOVA summary for 9th week: $\mathrm{F}(4,10)=59.05$; $\mathrm{P}<0.0001$; Control vs. SCI $\mathrm{P}<0.0001)$. At the 9 th week, these animals were not able to support their body weight, and the motor activity of their hindlimbs consisted of extensive movements in all three joints and 'sweeping', which was usually restricted to one pelvic extremity.

None of the treatments improved the final motor scores compared to the SCI group. However, there were significantly lower scores in the 3rd, 4th, 7th and 8th weeks (SCI vs. en. medium $\mathrm{P}<0.05$ ) in the neurological outcome of the group where the enriched medium was used. Final outcome was $3.0 \pm 2.65$ (SCI vs. en. medium, $\mathrm{P}=0.0545$ ). In the group treated with $4^{\circ} \mathrm{C}$ saline, there was transient improvement of motor functions between the $3 \mathrm{rd}$ and 7 th week of the follow up period 

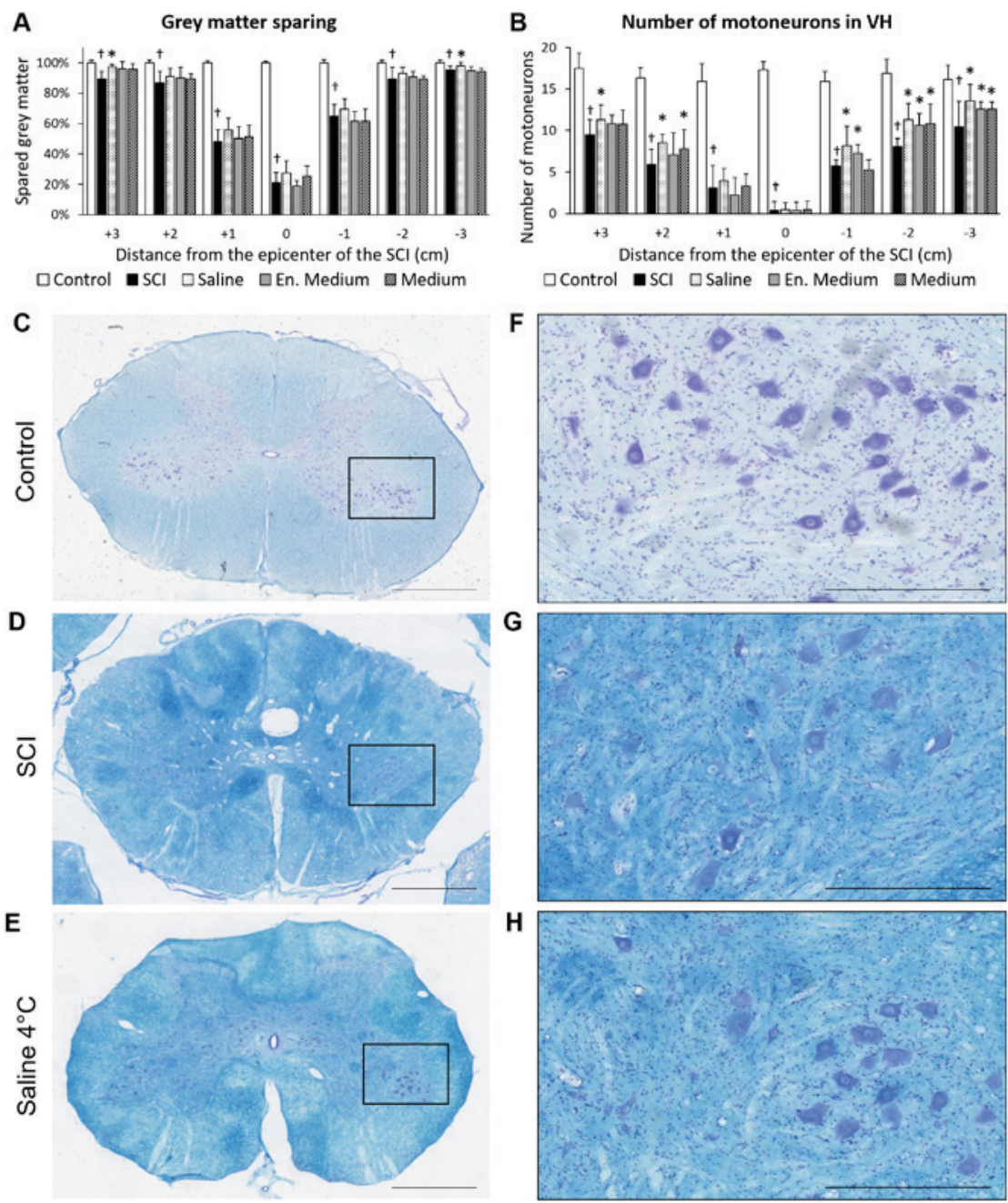

Figure 5. Experiment 1. (A and B) Gray matter sparing and preservation of motoneurons 9 weeks after SCI and hypothermic treatment with saline, en. medium or medium, performed on transverse sections dyed with Luxol fast blue and cresyl violet staining. Transverse spinal cord sections taken from caudal segments (-3) of (C) control, (D) after SCI and (E) treatment with cold saline. (F-H) High-power microphotographs of the boxed areas in C-E indicated motoneurons. Data are demonstrated as the mean \pm standard deviation. Ordinary one-way analysis of variance followed by Sidak's multiple comparison test was used for the assessment of differences between experimental groups in each segment separately. (A) Grey matter sparing. 'P<0.001 vs. Control; " $\mathrm{P}<0.05$, vs. SCI. (B) Number of motor neurons in VHs. 'P<0.0001 vs. Control; "P<0.05 vs. SCI. Scale bar in C-E, $2 \mathrm{~mm}$; in F-H, $500 \mu \mathrm{m}$. SCI, spinal cord injury; en. medium, enriched medium; $\mathrm{VH}$, ventral horn.

in comparison to the SCI group but the differences did not reach statistical significance. No differences were observed at the end point of the survival period.

Macroscopic changes at the lesion site. After 9 weeks, the spinal cord was markedly narrowed at the injury site (Fig. 4Ab). When removing the dura mater, we noted extensive fibrotic adhesions between the dura and underlying spinal cord tissue. On transversally-cut $1 \mathrm{~cm}$ segments, the central part contained a distorted cavity spreading in both cranial and caudal directions from the epicenter. The size of the cavity seemed to be slightly reduced in hypothermia-treated groups. No differences could be seen in the animals treated with medium or enriched medium.

Histological outcome. The cross-sectional areas of spared white and grey matter tissue on histological sections, taken from seven consecutive spinal cord segments, were measured. Nine weeks after SCI, the lesion formed a distorted spindle-shaped cavity. The data from morphometric analyses form a V-shaped curve which corresponds to the amount of preserved tissue in the damaged spinal cord (Figs. 4 and 5).

The most affected area was the epicenter of the injury (segment 0 ) where the white matter sparing corresponded to $26.20 \% \pm 6.99$. A detailed analysis of spared white matter was carried out by dividing it into dorsal, lateral and ventral columns (Fig. 4). We assessed the volume of spared white matter columns and found differences indicating the largest loss of tissue in the dorsal columns. The volumes of preserved white matter ranked in descending order: Ventral columns $(74.21 \% \pm 6.73)>$ lateral columns $(69.14 \% \pm 6.05)>$ dorsal columns $(61.69 \% \pm 5.45)$.

Nine weeks after SCI, the gray matter preservation was quite low at the lesion site $(20.99 \pm 6.59 \%)$ and in segments near the injury epicenter $(48.26 \pm 7.53 \%$ at +1 and $65.00 \pm 7.56 \%$ at -1 segment) (Fig. 5A). In addition, we counted the number of motoneurons in seven consecutive segments. The average number of motoneurons in the VHs of control animals was $16.58 \pm 1.54$. SCI + durotomy significantly reduced the cumulative number of motoneurons to $6.17 \pm 1.73$. A large 


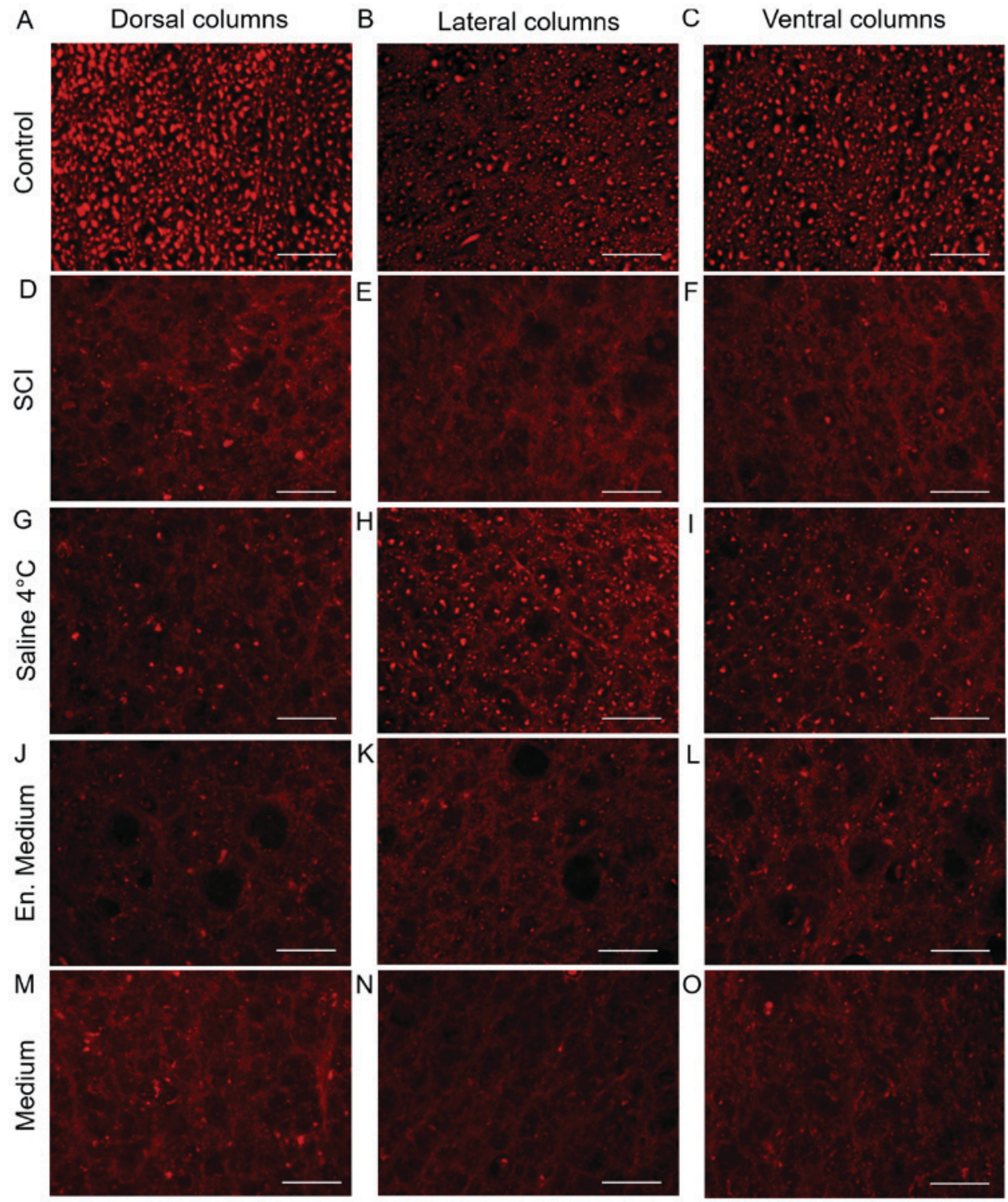

Figure 6. Experiment 1. Representative images of neurofilament immunohistochemistry. Sections were taken from +1 segment of transverse spinal cord sections (dorsal, lateral and ventral columns) from (A-C) control, (D-F) after SCI and subsequent hypothermic treatment with (G-I) cold saline, (J-L) en. medium or (M-O) medium. Scale bar, $100 \mu \mathrm{m}$. SCI, spinal cord injury; en. medium, enriched medium.

necrotic focus could be seen in the epicenter of the injury, where the number of motoneurons dropped to $0.39 \pm 1.04$. The number of motoneurons increased gradually along with the distance from the epicenter (Fig. 5B). Occasionally occurring motoneurons were observed up to $1 \mathrm{~cm}$ in rostro-caudal direction; there were $3.11 \pm 2.70$ cells rostrally and $5.72 \pm 0.75$ cells caudally. The motoneurons were clearly detectable $2 \mathrm{~cm}$ from the epicenter, although their number was still quite low (5.94 \pm 1.80 rostrally and $8.06 \pm 1.00$ caudally) in comparison with controls. There was only a slight increase in occurrence of motoneurons in segment $+3(9.5 \pm 1.79)$ and in segment -3 (10.44 \pm 3.05$)$ (Fig. 5B).

Morphometric analyses indicated that individual treatments had positive effect on tissue sparing after SCI. The most prominent improvement was detected in the white matter, where $4^{\circ} \mathrm{C}$ saline positively affected tissue sparing especially in the dorsal and lateral columns in almost all rostro-caudal segments. Hypothermia with medium and/or enriched medium positively affected the white matter integrity in the rostral segments of the dorsal and lateral columns (Fig. 4B and C). Significant sparing $(\mathrm{P}<0.05)$ was also found in the caudal segment distant from the epicenter of the injury in the group treated with enriched medium (Fig. 4C). No significant differences were noted in the ventral columns. The hypothermia treatment was less pronounced in the grey matter. The largest effect could be seen after $4^{\circ} \mathrm{C}$ saline treatment, especially in the segments distant from the epicenter. The most prominent improvement in number of motoneurons was noticed after hypothermia in the caudal segments (Fig. 5B). Significant improvement in the rostral segments was visible only in the saline or medium treated groups (Fig. 5B).

Imunohistochemistry. SMI-312 immunolabeling was performed to visualize individual axons in the white matter and to count their number in individual areas of interest (Figs. 2, 6 and 7). These data characterize the density of axons in selected areas of the dorsal, lateral and ventral columns, and their changes after SCI (Fig. 7). Nine weeks after SCI, loss of SMI-312-positive axons was significant in all white matter 
A

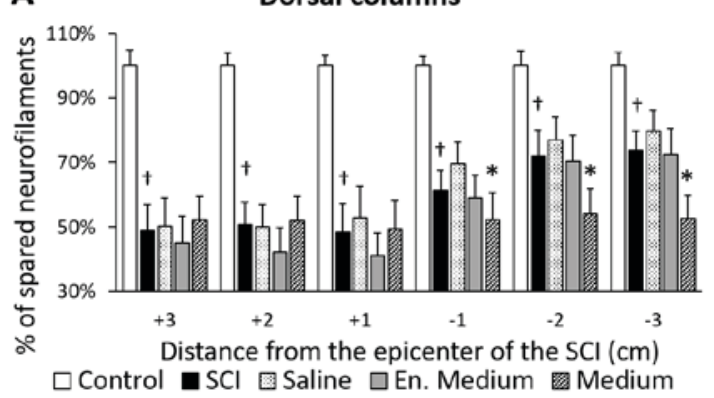

B
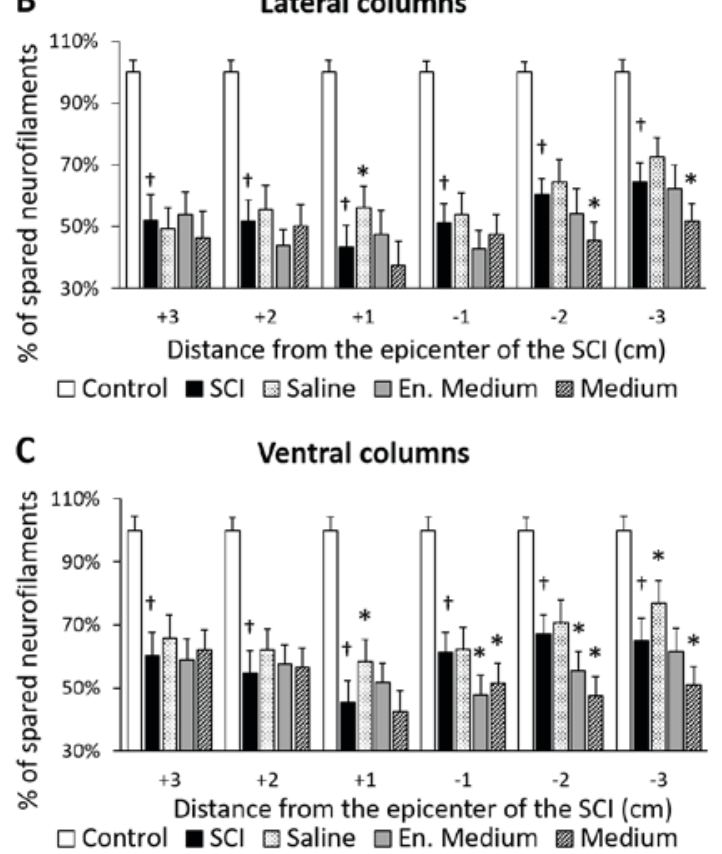

Figure 7. Experiment 1. Number of neurofilaments (expressed as percentage of $\mathrm{NF} / \mathrm{mm}^{2}$ ) in the (A) dorsal, (B) lateral and (C) ventral columns 9 weeks after SCI and hypothermic treatment with cold saline, en. medium or medium. The number of neurofilaments was evaluated bilaterally from ten randomly-selected transverse slices of each spinal cord block $(3 \mathrm{~cm}$ rostrally and $3 \mathrm{~cm}$ caudally from the epicenter of injury). Data are presented as the mean \pm standard deviation. Ordinary one-way analysis of variance followed by Sidak's multiple comparison test was used for the assessment of differences between experimental groups; each segment was assessed separately. ${ }^{\dagger} \mathrm{P}<0.0001$ vs. Control; ${ }^{*} \mathrm{P}<0.05$ vs. SCI. SCI, spinal cord injury; en. Medium, enriched medium.

columns along the rostro-caudal axis. The most affected were the lateral columns. The white matter disintegrity after SCI did not allow the number of neurofilaments to be quantified at the lesion site (segment 0 ).

Hypothermic treatment with $4^{\circ} \mathrm{C}$ saline increased the number of NF in all columns in comparison to the SCI. However, this improvement was significant ( $\mathrm{SCI}$ vs. saline $\mathrm{P}<0.05$ ) only in the lateral ( +1 segment) and ventral columns ( +1 and -3 segments). Hypothermia with medium negatively influenced the number of NF in the caudal segments (Fig. 7A-C).

\section{Experiment 2: Intact dura mater}

Behavioral assessment. The outcomes of minipigs in this experiment were very similar to those in Experiment 1 (Fig. 8). One week after SCI, the animals suffered complete paraplegia with almost no movement ability in all joints of the hind limbs

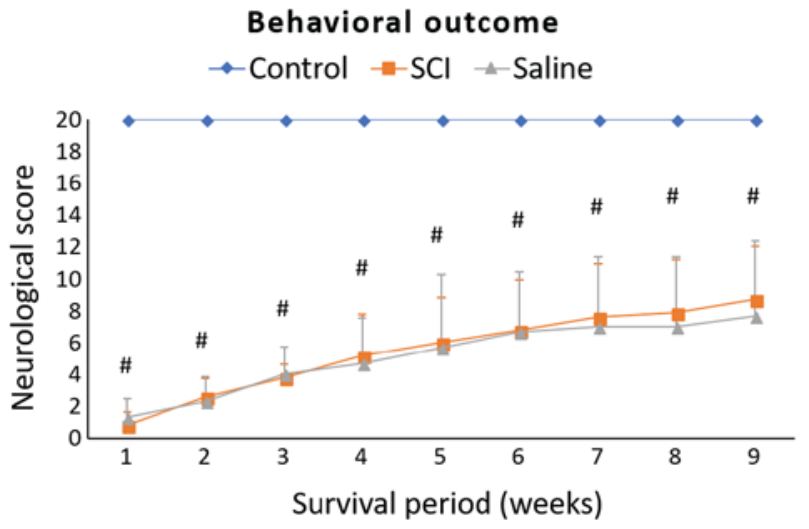

Figure 8. Experiment 2. Behavioral recovery of animals during 9-week survival period after SCI and subsequent hypothermia with saline. The scoring points range from complete paraplegia (point zero) to normal hindlimb function (point 20). Data are presented as the mean \pm standard deviation. Ordinary one-way analysis of variance followed by Sidak's multiple comparison test was used for the statistical analysis and each week was assessed separately. ${ }^{\#} \mathrm{P}<0.0001$, Control vs. SCI. SCI, spinal cord injury.

(ANOVA summary for 1st week: $\mathrm{F}(2,6)=495.5 ; \mathrm{P}<0.0001$; Control vs. SCI $\mathrm{P}<0.0001)$. At the end of the survival period, the score was $8.7 \pm 3.35$ points (ANOVA summary for 9th week: F $(2,6)=13.41 ; \mathrm{P}=0.0028$; Control vs. $\mathrm{SCI} \mathrm{P}=0.0051)$.

We did not notice any significant differences between the SCI group and the saline treated group $\left(24^{\circ} \mathrm{C}\right)$ at any time point during the whole survival period. The final neurological score was 7.67 \pm .73 (SCI vs. Saline $\mathrm{P}=0.9683$ ).

Histological outcome. The pattern of spinal cord tissue disintegrity after SCI was quite similar to that described in Experiment 1 (Figs. 9 and 10). At the lesion epicenter, the cumulative white matter sparing was $31.48 \% \pm 7.45$ and the spared gray matter was $23.7 \% \pm 4.35$. The volumes of preserved white matter ranked in descending order: ventral columns $(77.91 \% \pm 7.48)>$ dorsal columns $(75.54 \% \pm 5.89)>$ lateral columns $(72.23 \% \pm 6.35)$.

After $24^{\circ} \mathrm{C}$ saline treatment, there was an increase in white matter preservation (Fig. 9B-D). The area of preserved white matter was significant $(\mathrm{SCI}$ vs. saline $\mathrm{P}<0.05$ ) at several levels of the evaluated segments in the dorsal and lateral columns. The largest differences were noted in the lateral columns where hypothermia increased white matter preservation by $13.71 \% \pm 4.75$ (Fig. 9C). This improvement was significant along the rostro-caudal axis from +2 to -2 segment. The gray matter integrity was influenced as well (Fig. 10). Quantitative analysis revealed overall improvement by $16.68 \pm 5.76 \%$ in comparison to the SCI group. The improvement was significant (SCI vs. saline $\mathrm{P}<0.05$ ) in all segments except for the epicenter itself (Fig. 10A). The number of motoneurons was also improved by saline treatment (Fig. 10B). As shown in Fig. 10B, the number of motoneurons dropped from the initial value of $16.58 \pm 1.54$ cells in the control group to cumulative $5.7 \pm 1.78$ motoneurons in the SCI group. The number of motoneurons was significantly higher in all segments caudal to the injury epicenter (Fig. 10B). The cumulative number of motoneurons in the $\mathrm{VHs}$ in the saline-treated group increased to $6.9 \pm 1.57$ cells. 
A

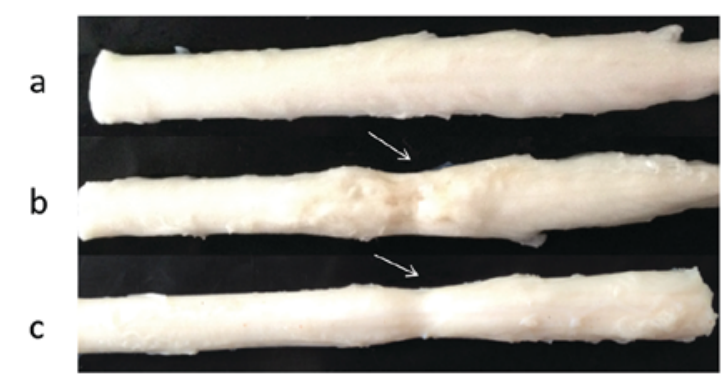

C

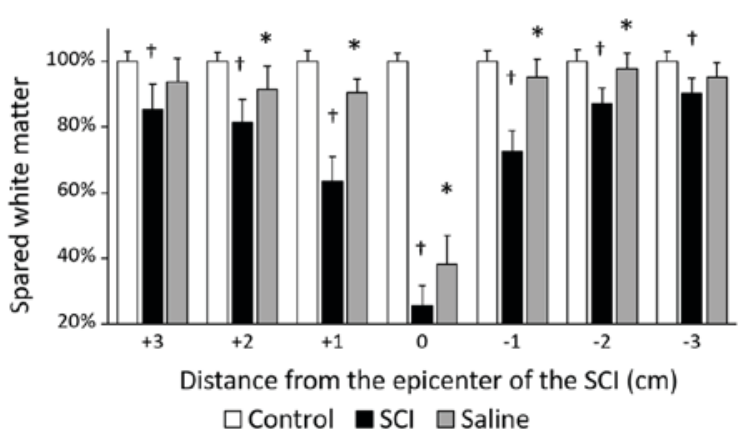

B

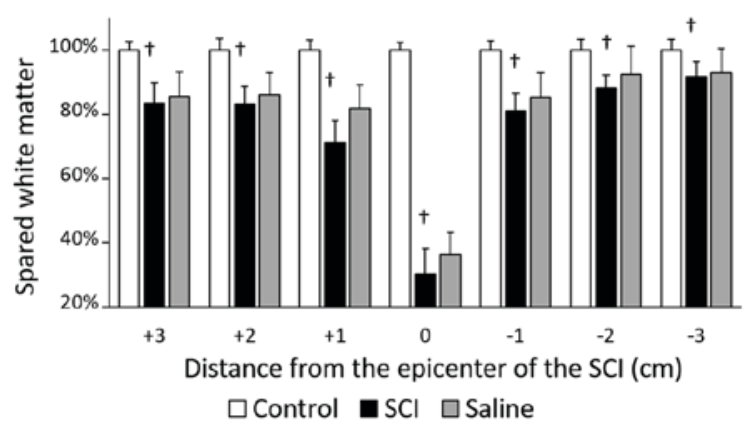

D

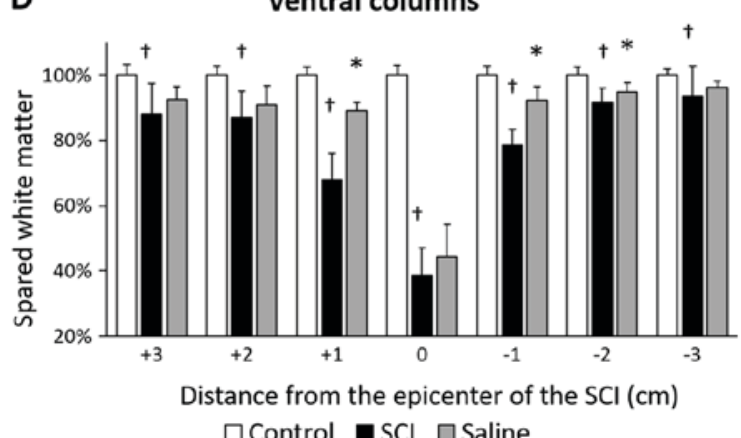

Figure 9. Experiment 2. (A) Macroscopic images of spinal cords and white matter sparing in spinal cord columns 9 weeks after SCI and saline treatment. Arrows point to the epicenter of the injury. Spinal cord of (Aa) control, $(\mathrm{Ab})$ after spinal cord injury and (Ac) subsequent hypothermic treatment with saline at room temperature. White matter sparing in (B) dorsal, (C) lateral and (D) ventral columns. Data are the mean values \pm standard deviation. Ordinary one-way analysis of variance followed by Sidak's multiple comparison test was used for the assessment of differences between experimental groups in each segment separately. ${ }^{\dagger} \mathrm{P}<0.0001$ vs. Control; ${ }^{*} \mathrm{P}<0.05$ vs. SCI. SCI, spinal cord injury.

Imunohistochemistry. Nine weeks after SCI, the density of neurofilaments strongly decreased in all white matter columns (Figs. 11 and 12). Again, the lowest density of SMI-312 positive axons $(59.16 \pm 5.57 \%$ of spared neurofilaments) was identified in the lateral columns.

Although saline hypothermia had beneficial influence on neurofilament's preservation in all white matter columns (Figs. 11 and 12), the effect of treatment was more prominent in the dorsal and the lateral columns than in the ventral columns (Fig. 12).

Durotomy vs. intact dura mater. To determine the effect of durotomy, the data from both SCI groups from Experiment 1 (durotomy) and Experiment 2 (intact dura mater) are summarized in Fig. 13. We detected significantly better neurological outcome in animals with intact dura mater at the 4th-6th weeks $(\mathrm{P}<0.05)$, but the differences were non-significant at the end of the survival period (Fig. 13A).

The animals with intact dura mater also showed improvement in white matter preservation (segments $+3,+2,-2,-3$ ) and in density of SMI-312 positive axons (from +3 to +1 segments) (Fig. 13B and D). In contrast, both the grey matter sparing and preservation of motoneurons deteriorated in segments distant from the lesion site (Fig. 13C and D).

Correlation. To determine the sensitivity of the individual outcome parameters, we utilized the data from all groups from experiments 1 and $2(n=24)$ and performed a Spearman's correlation analysis between individual outcome parameters and final behavioral scores (Fig. 14).
We found moderately positive correlation between the neurological score and the number of neurofilaments at 9 weeks $(\mathrm{r}=0.6746 ; \mathrm{P}=0.0003)$ followed by weakly positive correlation between neurological score and number of motoneurons in the VHs $(\mathrm{r}=0.4660 ; \mathrm{P}=0.0217)$, cumulative white matter sparing $(\mathrm{r}=0.4708 ; \mathrm{P}=0.0202)$ and cumulative grey matter sparing $(\mathrm{r}=0.4760 ; \mathrm{P}=0.0187)$.

\section{Discussion}

In the present study, we tested the efficacy of local hypothermia on the outcome parameters in a minipig SCI model utilizing a computer-controlled impact device. Two different approaches to local hypothermia treatment were compared: i) Post-SCI durotomy allowing direct access of perfusion solutions to the spinal cord tissue, and ii) post-SCI treatment with intact dura mater.

Comparison of the outcomes from both SCI groups (in Experiments 1 and 2) demonstrates that the durotomy itself had no impact on the final neurological outcome. However, the recovery of the animals treated with durotomy was noticeably slower and the neurological score of these minipigs was significantly worse from the 4th to 6th week. This finding was supported by our histological observations where the white matter outcome parameters showed significantly worsened tissue and axonal preservation in the group treated with durotomy. Based on data from the literature, durotomy itself performed soon after SCI could be beneficial. The positive effects are generally attributed to alleviated intraspinal pressure, subsequent improvement in blood perfusion of the injured tissues, and also to reduction of 
A

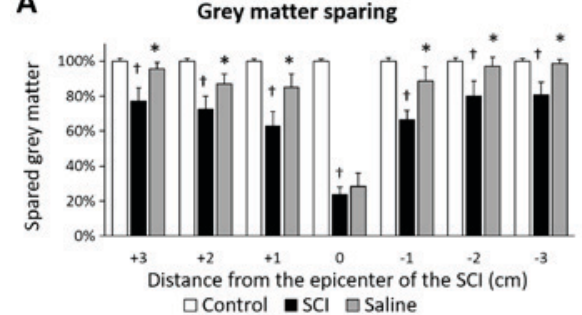

C

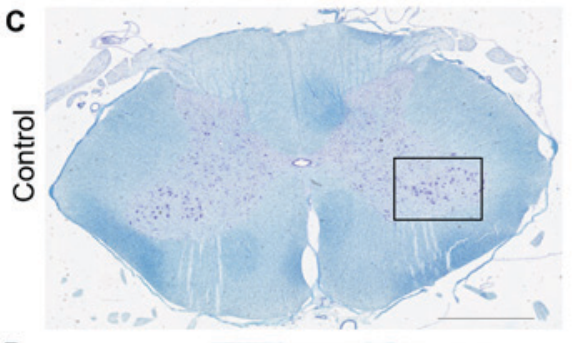

D

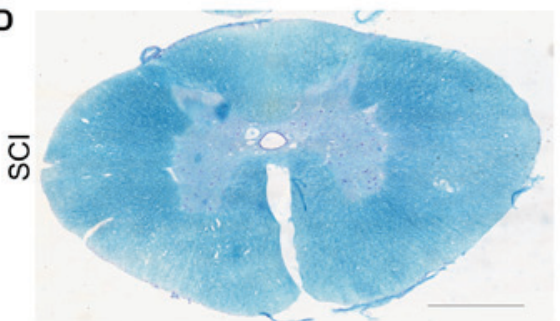

E

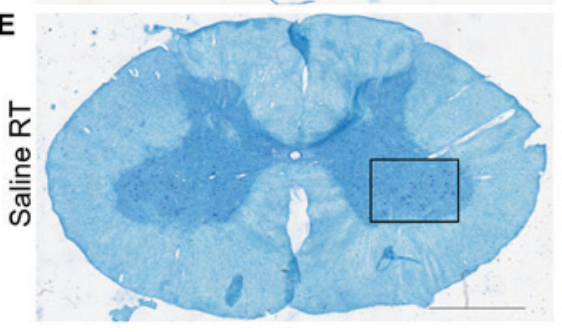

B
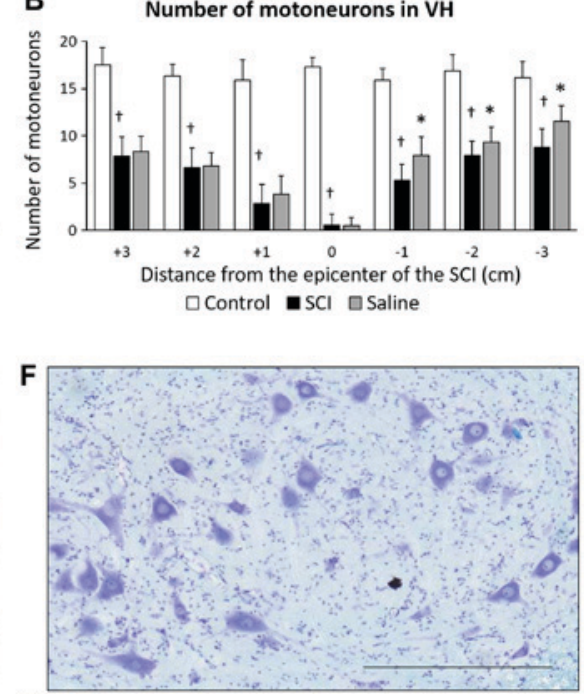

G

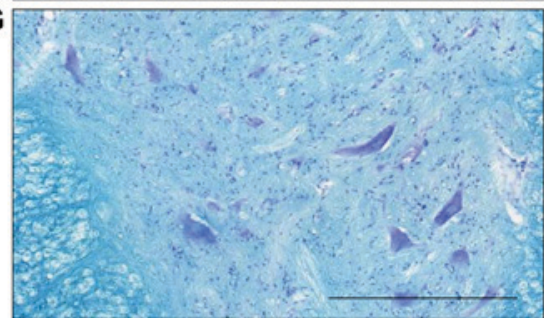

H

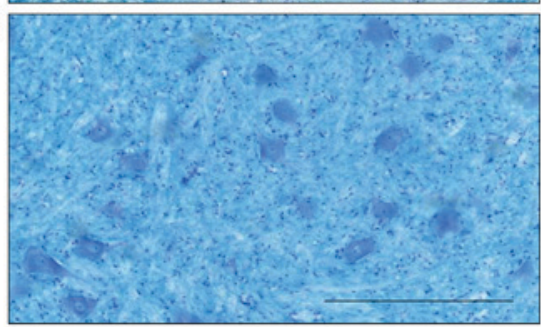

Figure 10. Experiment 2. Gray matter sparing and preservation of motoneurons 9 weeks after SCI and hypothermic treatment with saline performed on transverse sections dyed with Luxol fast blue and cresyl violet staining (A-B). Transverse spinal cord sections taken from caudal segments (-3) of (C) control, (D) after SCI and (E) treatment with saline. (F-H) High-power microphotographs of the boxed areas in C-E showing motoneurons. Data are the mean values \pm standard deviation. Ordinary one-way analysis of variance followed by Sidak's multiple comparison test was used for the assessment of differences between experimental groups in each segment of spinal cord separately. (A) Grey matter sparing; ${ }^{\dagger} \mathrm{P}<0.05$ vs. Control; ${ }^{*} \mathrm{P}<0.05$ vs. SCI. (B) Number of motor neurons in VHs; 'P $\mathrm{P}<0.0001$, vs. Control; " $\mathrm{P}<0.05$ vs. SCI. Scale bar in C-E, $2 \mathrm{~mm}$; in F-H, $500 \mu \mathrm{m}$. SCI, spinal cord injury; VH, ventral horn.

lesion volume due to attenuation of post-traumatic cystic cavitation (60-63). Beneficial influence achieved through durotomy applied after acute SCI was described as early as in 1988 by Perkins and Deane (64). Based on later studies, spinal cord decompression with durotomy has substantial effect on neurological outcome $(60,62,63)$. It has been described, in terms of its application, not worsening the neurological state of the patients in clinical studies $(65,66)$. Iannotti et al $(67)$ reported beneficial effects of durotomy itself and combined with an allograft patch performed $4 \mathrm{~h}$ after injury. These researchers found that cases with durotomy showed improved recovery and significant reduction in lesion volume.

On the other hand, durotomy disrupts the natural circulation of cerebrospinal fluid (CSF), which can be associated with adverse effects. Smith et al (63) showed that durotomy itself had detrimental effect and increased scar and cavity formation. There are evidences that even more severe complications (e.g., low-CSF-pressure headache with meningitis or transient quadriplegia) could be associated with durotomy (68). Jones et al $(69,70)$ performed two separate studies utilizing the porcine model of weight drop and compression SCI followed by decompression surgery four h after primary injury. Both studies describe in detail the eventual consequences of the performed durotomy. The first study showed that decompression following SCI resulted in varying degrees of spinal cord swelling, occlusion of the subarachnoid space and blockage of CSF flow. According to them, an important factor in this process is the initial severity of the injury. These observations may partly explain the lack of benefit of decompression in some patients. They suggest a need to reduce spinal cord swelling in order to optimize the clinical outcome after acute SCI (69). The second study posits that intradural swelling may induce secondary pathology due to interruption of normal CSF flow and constraints on swelling by the surrounding meninges, leading to inconclusive results of decompression and neurological outcome following SCI (70). In our study we observed spinal cord swelling in all groups which underwent durotomy. In spite of the treatment procedures, the swelling persisted after five $h$, when the dura mater was sutured in order to stop CSF leakage and development of meningitis. We assume that 

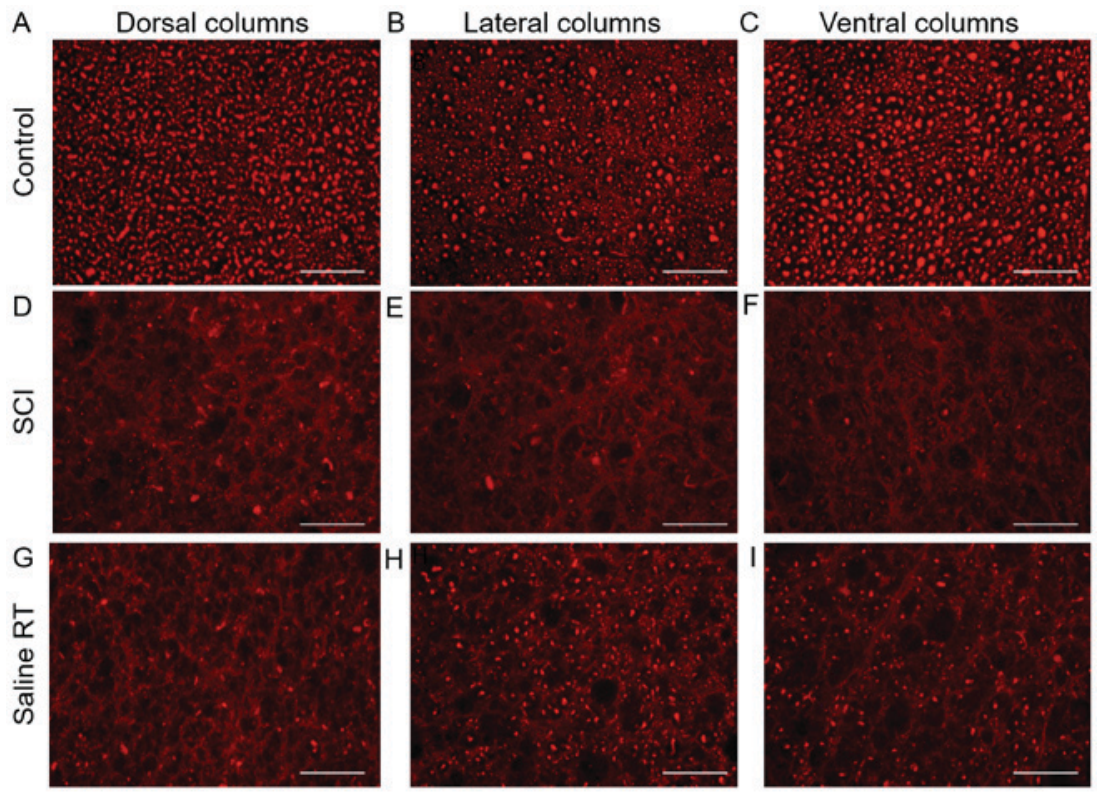

Figure 11. Experiment 2. Representative images of neurofilament immunohistochemistry. Sections were taken from +1 segment of transverse spinal cord sections (dorsal, lateral and ventral columns) from (A-C) control, (D-F) after SCI and subsequent (G-I) hypothermic treatment with saline. Scale bar, $100 \mu \mathrm{m}$. SCI, spinal cord injury; RT, room temperature.
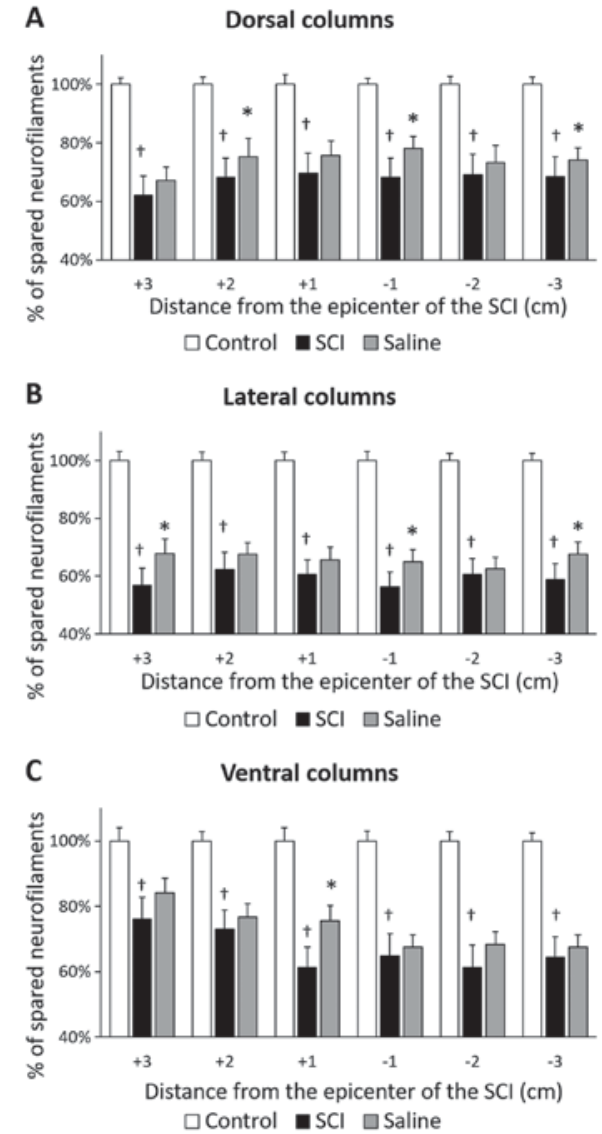

Figure 12. Experiment 2. Number of neurofilaments (expressed as percentage of neurofilaments $/ \mathrm{mm}^{2}$ ) in white matter columns 9 weeks after SCI in the (A) dorsal, (B) lateral and (C) ventral columns after hypothermic treatment with saline. The number of neurofilaments was evaluated bilaterally from ten randomly-selected transverse slices of each spinal cord block $(3 \mathrm{~cm}$ rostrally and $3 \mathrm{~cm}$ caudally from the epicenter of injury). Data are presented as the mean \pm standard deviation. Ordinary one-way analysis of variance followed by Sidak's multiple comparison test was used for the assessment of differences between experimental groups in each segment separately. ${ }^{\dagger} \mathrm{P}<0.0001$ vs. Control; ${ }^{*} \mathrm{P}<0.05$ vs. SCI. SCI, spinal cord injury. delayed closure of the dura encircling the swollen segments of the spinal cord could be one of the reasons for the worsened outcomes noted in the animals that underwent durotomy.

Schumacher et al (71) reported an association between neurofilament loss and impaired hind-limb motor function after SCI. Significantly lower white matter integrity and reduction of neurofilaments in durotomy-treated animals could reflect multiple factors causing variable outcomes following the interruption of long-projection pyramidal (lateral corticospinal) and extrapyramidal (rubrospinal and reticulospinal) tracts. Neurofilaments are particularly abundant in large myelinated axons and are essential for axon radial growth and axon caliber maintenance during development $(72,73)$. Wang et al (74) reported that NF gene transcriptional regulation is crucial for NF expression, predominantly in axonal regeneration and degenerative diseases.

The opposite effect was seen in gray matter. Quantitative analysis confirmed the loss of gray matter and motoneurons at the lesion site and in rostro-caudal segments up to $2 \mathrm{~cm}$ in both SCI models. These changes were less dramatic in the SCI-durotomy group but only in segments (+3 and -3), i.e., distant from the lesion site. The response of motoneurons to SCI depends on their ability to handle calcium. Previous results have indicated an unusually high influx of $\mathrm{Ca}^{2+}$ into motoneurons upon their stimulation (75-77). We have reported increased expression of parvalbumin, a $\mathrm{Ca}^{2+}$-binding protein, in motoneurons ten days after Th9 transection (78). The results suggest that this $\mathrm{Ca}^{2+}$-binding protein may rescue trauma-affected neuronal circuits involved in motor control.

Effects of hypothermia in Experiment 1. When planning to carry out therapeutic local hypothermia in the acute stage of spinal cord compression in minipigs, we took into consideration two critical aspects, i.e., the cooling conditions and the penetration of perfusion solutions, both essential for the success of treatment. Under certain circumstances, radical hypothermia 


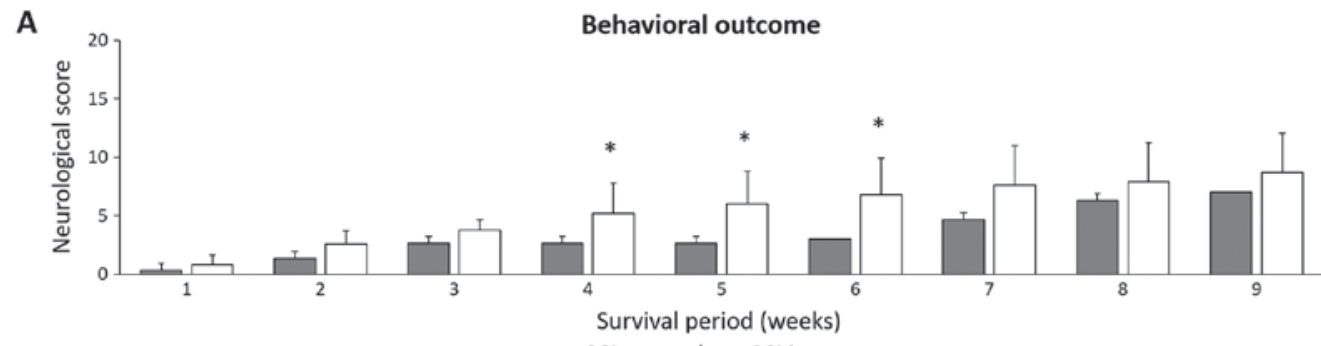

B

White matter sparing

$\square \mathrm{SCl}$ opened $\square \mathrm{SCl}$ intact

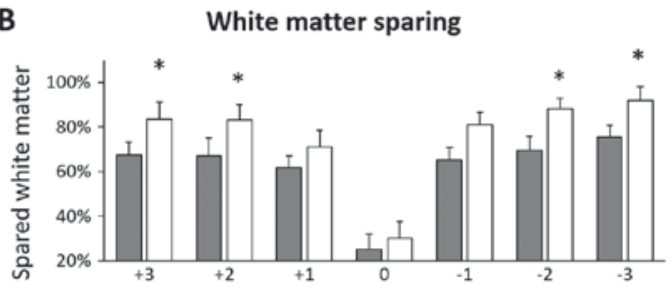

C Grey matter sparing

Distance from the epicenter of the $\mathrm{SCl}(\mathrm{cm})$

$\square \mathrm{SCl}$ opened $\square \mathrm{SCl}$ intact

D

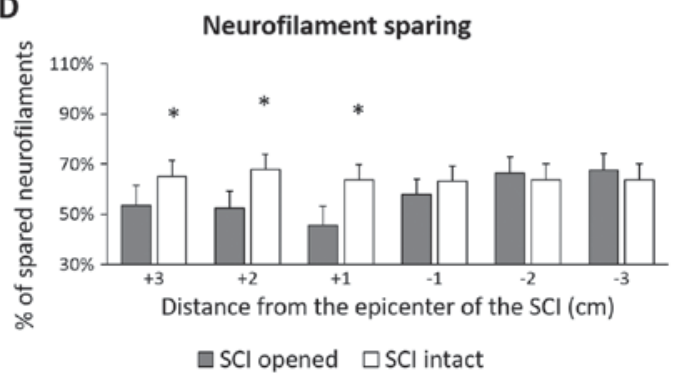

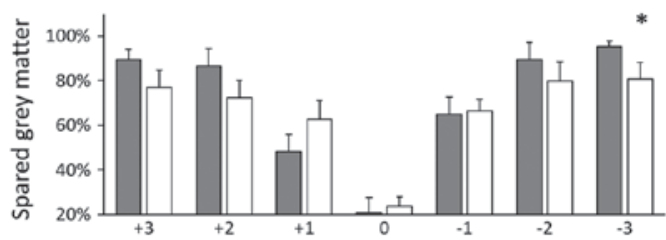

Distance from the epicenter of the $\mathrm{SCl}(\mathrm{cm})$

$\square \mathrm{SCl}$ opened $\square \mathrm{SCl}$ intact

$\mathbf{E}$

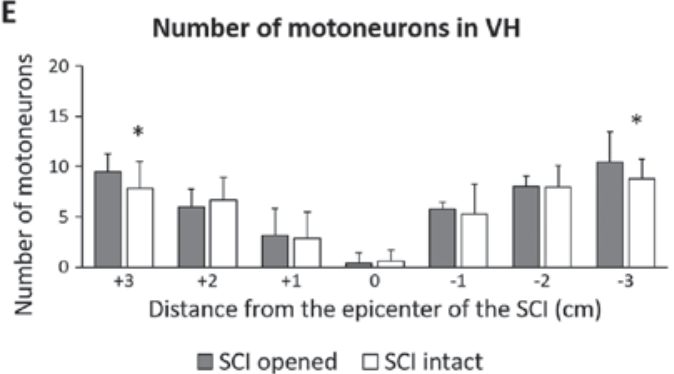

Figure 13. Comparison of outcome parameters in SCI groups (SCI opened and SCI intact dura mater). The animals survived for 9 weeks. Data are the mean values \pm standard deviation. Unpaired Student $t$ test was used for statistical evaluation of data. "P<0.05 SCI opened vs. SCI intact. (A) Behavioral recovery, (B) cumulative white matter sparing, (C) cumulative grey matter sparing, (D) number of neurofilaments and (E) number of motoneurons in VHs were assessed. SCI, spinal cord injury; $\mathrm{VH}$, ventral horn.

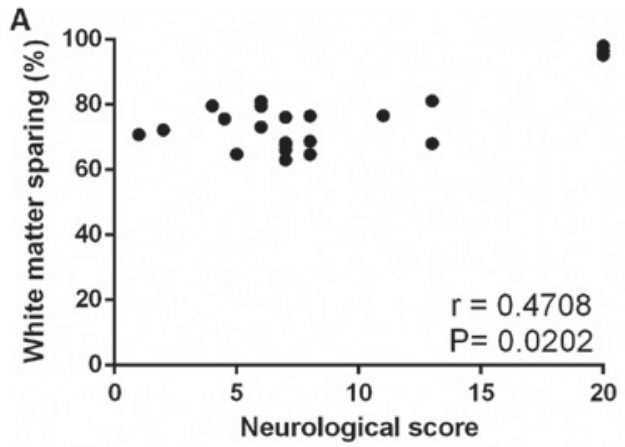

C

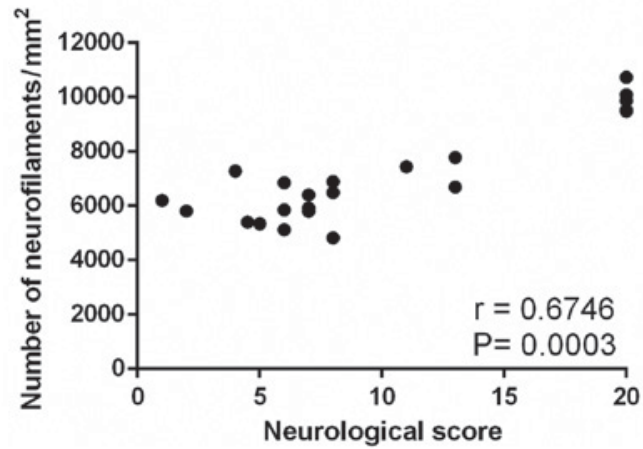

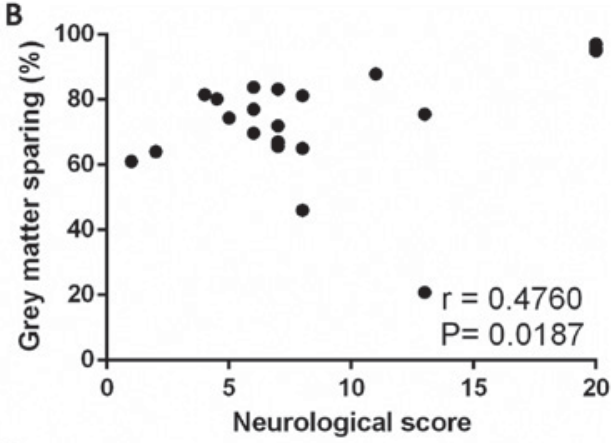

D

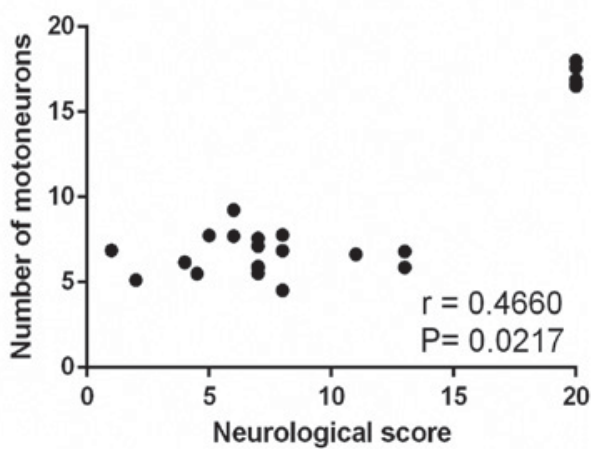

Figure 14. Scatterplots illustrating relationship between final neurological score of animals from all experimental groups and (A) cumulative white matter sparing, (B) cumulative grey matter sparing, (C) number of neurofilaments and (D) number of motoneurons in spinal cord VHs. Indicated are the Spearman rank correlation coefficients (r) and the P-values. The number of XY pairs is 24 . VH, ventral horn. 
appears more promising than modest hypothermia (79-81). Vanický et al (82) reported that deep spinal cord hypothermia $\left(\mathrm{t}<15^{\circ} \mathrm{C}\right)$ via epidural cooling with $5^{\circ} \mathrm{C}$ saline provided effective protection against long-lasting spinal cord ischemia in rabbits. We have previously shown the benefit of five hours of local hypothermia $\left(\mathrm{t}=19^{\circ} \mathrm{C}\right)$ in an $8 \mathrm{~N}$ and $15 \mathrm{~N}$ computer-controlled compression model of SCI in minipig (57). The results indicated that modulation of the microcircuits leading to better functional outcome may depend on the preservation of axons in the lateral columns of cranial and caudal segments immediately adjacent to the lesion, and the protection of neurofilaments in the same segments of lateral funiculi (57).

In the present study, durotomy allowed direct penetration of solutions (saline, medium or enriched medium) through the outer surface of the uncovered spinal cord within $3 \mathrm{~cm}$ in cranio-caudal direction. However, none of these treatments improved the final neurological outcome, and quite surprisingly, the application of the cold enriched medium caused significant worsening of the scores which became apparent at the 4th week and persisted almost until the end of the survival period. Morphometric analyses of the lesion size indicated that individual treatment procedures did improve some tissue preservation in both the white and grey matter. Saline hypothermia activated the processes that led to better regeneration of the white matter within the dorsal and lateral columns in almost all cranio-caudal segments. We also found improvements in neurofilament expression and the sparing of grey matter/motoneurons. Earlier in vitro study showed that a particular neuronal population in monolayer cultures of dissociated murine spinal cord was especially sensitive to hypothermic stress (83). When the spinal cord cultures were exposed to the temperatures below $17^{\circ} \mathrm{C}$, the neuronal perikarya and dendrites swelled, with the majority of the swollen neurons dying during the phase of rewarming to $37^{\circ} \mathrm{C}$, while glial and other nonneuronal cell types were unaffected. The authors claimed that prolonged exposure (2-6 h) of monolayer cultures to the temperatures below $17^{\circ} \mathrm{C}$ caused significant neuronal death mediated primarily by the NMDA receptor-ion channel complexes in the dendro-somatic membranes. In the present study we report that the temperature of the saline (at 15 or $24^{\circ} \mathrm{C}$ ) significantly reduced motoneuron death. Surface cooling of the spinal cord creates a substantial temperature gradient within the cord tissue (84) which may differently influence the viability of spinal motoneurons in in vivo experiments.

These protective effects can be attributed to transient hypothermia. Previously, strong protective effects of local spinal cord hypothermia had been demonstrated in spinal cord ischemia experiments $(24,82,85,86)$. Local hypothermia was utilized in experimental studies after traumatic SCI as well. Cooling was generally initiated no later than $30 \mathrm{~min}$ after acute SCI, its duration varied between $20 \mathrm{~min}$ and $48 \mathrm{~h}$ and the temperature varied between $19^{\circ} \mathrm{C}$ up to $35^{\circ} \mathrm{C}$. In general, these studies showed that hypothermia is more effective when initiated early after injury and lasts for a longer time. Shorter duration may require more profound cooling to achieve similar effect (35). In general, these data suggest that long periods of local hypothermia are tolerated well and may improve long-term tissue sparing and functional outcome $(14,35,40-43,47,57,87)$.
Treatment with cold medium and/or enriched medium significantly preserved the white matter in dorsal ( +3 segment) and lateral ( +3 and +1 segment) columns located cranially to the lesion site. The medium negatively affected neurofilaments predominantly in the caudal segments and led to non-significantly lower behavioral outcome than in the SCI + durotomy group from the 7 th to 9 th week. In the case of the enriched medium-treated minipigs, the neurological outcome was very low during the whole survival period. It appears that low temperature of medium and/or enriched medium influenced the blood flow and slowed down the cell metabolism resulting in cell inability to profit from the ingredients contained in the cooling solutions. The mechanisms underlying protection by hypothermia are believed to be slowing down the enzymatic activity of reactions that require adenosine triphosphate (88). The results of our study confirm that exposure to low temperatures may be stressful for the cells treated with medium and/or enriched medium. It is still questionable whether increasing the target temperature during enriched medium/medium hypothermia could be able to improve histological/neurological outcomes.

Effect of hypothermia in Experiment 2. In Experiment 2 we tested a less invasive saline $\left(24^{\circ} \mathrm{C}\right)$ treatment through the intact dura mater, minimizing the risk of spinal parenchymal infection. This moderate hypothermia treatment had significant effect on tissue preservation, but this effect was not associated with improved motor recovery. Several studies described similar results, where spinal cord hypothermia protected tissue from excessive loss without significant improvement in neurological function $(41,57)$. Similarly, Teh et al (87) observed that hypothermia improved tissue preservation and neurological outcome during survival, but not the final neurological outcome. On the other hand, Casas et al (40) showed that regional cooling applied $30 \mathrm{~min}$ after moderate contusive SCI was not beneficial or detrimental in terms of tissue sparing, neuronal preservation, or locomotor outcome. They suggested, that this method of cooling may reduce blood flow in the injured spinal cord and exacerbate secondary injury.

The results of this pilot study extend the use of our reproducible minipig model for preclinical SCI experiments. The data indicate that further therapeutic interventions can modify the outcomes we have followed. The degree of injury we have used (18N SCI) is perhaps too severe for experimental therapy, and for observing any changes in neurological outcome, and less severe degrees of injury would be preferable. Our observations indicate that posttraumatic edema is a serious pathophysiological mechanism contributing to injury. When planning interventions with durotomy, prolonged duration of post-traumatic swelling should be taken into consideration. The optimal degree of hypothermia and its timing should be studied systematically. Further experimental/clinical studies are required to determine the optimal cooling parameters (therapeutic window, optimal temperature and duration) and to test the effectiveness of hypothermic therapy in various trauma-induced SCI models using large experimental animals.

\section{Acknowledgements}

The authors would like to thank Dr S. Gancarcikova from the University of Veterinary Medicine and Pharmacy (Kosice, 
Slovakia) for preparation of protocols approved by the State Veterinary and Food Administration and Mrs. A. Kosova for her technical assistance.

\section{Funding}

The present study was supported by the project: Formation and Development of a Diagnostic Procedure in the Rreatment of Trauma-Injured Spinal Cord (grant no. ITMS 26220220202), supported by the Research and Development Operational Program funded by the ERDF.

\section{Availability of data and materials}

The datasets used and/or analyzed during the current study are available from the corresponding authors on reasonable request.

\section{Authors' contributions}

MMars, NL and JG were involved in creating the study concept and designing the experiments. VL, AT, IC and PR were involved in anesthetizing animals and post-surgical animal care. MMars, IS, MG, IL, JK, IS Jr., JG and JP were involved in spinal cord compression and implantation of the perfusion chamber. JG, SP and MZ prepared the perfusion chamber. JG, MZ, SP and JP assisted in hypothermic treatment administration. JP, MZ, SP, JG, KB and MB were invovled in transcardial perfusion and spinal cord tissue preparation. MZ, SP, ER, MMart, AS and AK performed the immunohistochemical staining and histological procedures. PR, MZ, SP and JG performed the behavioral assessments. MZ, NL and DM performed data analysis. MZ and NL wrote the paper.

\section{Ethics approval and consent to participate}

The experimental protocols were prepared in accordance with the EC Council Directive (2010/63/EU) regarding the use of animals in research and approved by the State Veterinary and Food Administration of the Slovak Republic (decision no. 1319/13-221) as well as by the Ethical Commission of the University of Veterinary Medicine and Pharmacy in Kosice, Slovak Republic. All efforts were made to minimize the size of experimental groups and animal suffering.

\section{Patient consent for publication}

Not applicable.

\section{Competing interests}

The authors declare no conflicts of interest.

\section{References}

1. Tator $\mathrm{CH}$ : Review of treatment trials in human spinal cord injury: Issues, difficulties, and recommendations. Neurosurgery 59: 957-987, 2006.

2. Tator CH: Update on the pathophysiology and pathology of acute spinal cord injury. Brain Pathol 5: 407-413, 1995.

3. McDonald JW and Sadowsky C: Spinal-cord injury. Lancet 359: 417-425, 2002
4. Balentine JD: Pathology of experimental spinal cord trauma I. The necrotic lesion as a function of vascular injury. Lab Invest 39: 236-253, 1978.

5. Simard JM, Woo SK, Aarabi B and Gerzanich V: The Sur1-Trpm4 channel in spinal cord injury. J Spine Suppl 4: 002, 2013.

6. Rowland JW, Hawryluk GW, Kwon B and Fehlings MG: Current status of acute spinal cord injury pathophysiology and emerging therapies: Promise on the horizon. Neurosurg Focus 25: E2, 2008.

7. Bracken MB, Shepard MJ, Collins WF, Holford TR, Young W, Baskin DS, Eisenberg HM, Flamm E, Leo-Summers L, Maroon J, et al: A randomized, controlled trial of methylprednisolone or naloxone in the treatment of acute spinal-cord injury. Results of the Second National Acute Spinal Cord Injury Study. N Engl J Med 322: 1405-1411, 1990.

8. Wang $\mathrm{J}$ and Pearse DD: Therapeutic hypothermia in spinal cord injury: The status of its use and open questions. Int J Mol Sci 16: 16848-16879, 2015.

9. Kwon BK, Okon E, Hillyer J, Mann C, Baptiste D, Weaver LC, Fehlings $\mathrm{M}$ and Tetzlaff $\mathrm{W}$ : A systematic review of non-invasive pharmacologic neuroprotective treatments for acute spinal cord injury. J Neurotrauma 28: 1545-1588, 2011.

10. Tetzlaff W, Okon EB, Karimi-Abdolrezaee S, Hill CE, Sparling JS, Plemel JR, Plunet WT, Tsai EC, Baptiste D, Smithson LJ, et al: A systematic review of cellular transplantation therapies for spinal cord injury. J Neurotrauma 28: 1611-1682, 2011.

11. Wang B, Armstrong JS, Reyes M, Kulikowicz E, Lee JH, Spicer D, Bhalala U, Yang ZJ, Koehler RC, Martin LJ and Lee JK: White matter apoptosis is increased by delayed hypothermia and rewarming in a neonatal piglet model of hypoxic ischemic encephalopathy. Neuroscience 316: 296-310, 2016.

12. Martirosyan NL, Patel AA, Carotenuto A, Kalani MY, Bohl MA, Preul MC and Theodore N: The role of therapeutic hypothermia in the management of acute spinal cord injury. Clin Neurol Neurosurg 154: 79-88, 2017.

13. Ok JH, Kim YH and Ha KY: Neuroprotective effects of hypothermia after spinal cord injury in rats: Comparative study between epidural hypothermia and systemic hypothermia. Spine (Phila Pa 1976) 37: E1551-E1559, 2012.

14. Ha KY and Kim YH: Neuroprotective effect of moderate epidural hypothermia after spinal cord injury in rats. Spine (Phila Pa 1976) 33: 2059-2065, 2008

15. Lo TP Jr, Cho KS, Garg MS, Lynch MS, Marcillo AE, Koivisto DL, Stagg M, Abril RM, Patel S, Dietrich WD and Pearse DD: Systemic hypothermia improves histological and functional outcome after cervical spinal cord contusion in rats. J Comp Neurol 514: 433-448, 2009.

16. Crowe MJ, Bresnahan JC, Shuman SL, Masters JN and Beattie MS: Apoptosis and delayed degeneration after spinal cord injury in rats and monkeys. Nat Med 3: 73-76, 1997.

17. Shuman SL, Bresnahan JC and Beattie MS: Apoptosis of microglia and oligodendrocytes after spinal cord contusion in rats. J Neurosci Res 50: 798-808, 1997.

18. Dumont RJ, Okonkwo DO, Verma S, Hurlbert RJ, Boulos PT, Ellegala DB and Dumont AS: Acute spinal cord injury, part I: Pathophysiologic mechanisms. Clin Neuropharmacol 24: 254-264, 2001

19. Shibuya S, Miyamoto O, Janjua NA, Itano T, Mori S and Norimatsu H: Posttraumatic moderate systemic hypothermia reduces TUNEL positive cells following spinal cord injury in rat. Spinal Cord 42: 29-34, 2004.

20. Dietrich WD, Atkins CM and Bramlett HM: Protection in animal models of brain and spinal cord injury with mild to moderate hypothermia. J Neurotrauma 26: 301-312, 2009.

21. Grulova I, Slovinska L, Nagyova M, Cizek M and Cizkova D: The effect of hypothermia on sensory-motor function and tissue sparing after spinal cord injury. Spine J 13: 1881-1891, 2013.

22. Seo JY, Kim YH, Kim JW, Kim SI and Ha KY: Effects of therapeutic hypothermia on apoptosis and autophagy after spinal cord injury in rats. Spine (Phila Pa 1976) 40: 883-890, 2015.

23. Strauch JT, Lauten A, Spielvogel D, Rinke S, Zhang N, Weisz D, Bodian CA and Griepp RB: Mild hypothermia protects the spinal cord from ischemic injury in a chronic porcine model. Eur J Cardiothorac Surg 25: 708-715, 2004.

24. Yoshitake A, Mori A, Shimizu H, Ueda T, Kabei N, Hachiya T, Okano $\mathrm{H}$ and Yozu R: Use of an epidural cooling catheter with a closed countercurrent lumen to protectagainst ischemic spinal cord injury in pigs. J Thorac Cardiovasc Surg 134: 1220-1226, 2007. 
25. Inoue S, Mori A, Shimizu H, Yoshitake A, Tashiro R, Kabei N and Yozu R: Combined use of an epidural cooling catheter and systemic moderate hypothermia enhances spinal cord protection against ischemic injury in rabbits. J Thorac Cardiovasc Surg 146: 696-701, 2013.

26. Saito T, Saito S, Yamamoto H and Tsuchida M: Neuroprotection following mild hypothermia after spinal cord ischemia in rats. J Vasc Surg 57: 173-181, 2013.

27. Fay T: Early experiences with local and generalized refrigeration of the human brain. J Neurosurg 16: 239-260, 1959.

28. Tuzgen S, Kaynar MY, Güner A, Gümüștas K, Belce A, Etuş V and Ozyurt E: The effect of epidural cooling on lipid peroxidation after experimental spinal cord injury. Spinal Cord 36 654-657, 1998.

29. Kalayci M, Coskun O, Cagavi F, Kanter M, Armutcu F, Gul S and Acikgoz B: Neuroprotective effects of ebselen on experimental spinal cord injury in rats. Neurochem Res 30: 403-410, 2005

30. Ji X, Luo Y, Ling F, Stetler RA, Lan J, Cao G and Chen J: Mild hypothermia diminishes oxidative DNA damage and pro-death signaling events after cerebral ischemia: A mechanism for neuroprotection. Front Biosci 12: 1737-1747, 2007.

31. Duz B, Kaplan M, Bilgic S, Korkmaz A and Kahraman S: Does hypothermic treatment provide an advantage after spinal cord injury until surgery? An experimental study. Neurochem Res 34: 407-410, 2009.

32. Topuz K, Colak A, Cemil B, Kutlay M, Demircan MN Simsek H, Ipcioglu O, Kucukodaci Z and Uzun G: Combined hyperbaric oxygen and hypothermia treatment on oxidative stress parameters after spinal cord injury: An experimental study. Arch Med Res 41: 506-512, 2010.

33. Karamouzian S, Akhtarshomar S, Saied A and Gholamhoseinian A: Effects of methylprednisolone on neuroprotective effects of delay hypothermia on spinal cord injury in rat. Asian Spine J 9: 1-6, 2015

34. Wang D and Zhang J: Effects of hypothermia combined with neural stem cell transplantation on recovery of neurological function in rats with spinal cord injury. Mol Med Rep 11: 1759-1767, 2015.

35. Xu X, Li N, Zhu L, Zhou Y and Cheng H: Beneficial effects of local profound hypothermia and the possible mechanism after experimental spinal cord injury in rats. J Spinal Cord Med 39: 220-228, 2015

36. Morino T, Ogata T, Takeba J and Yamamoto H: Microglia inhibition is a target of mild hypothermic treatment after the spinal cord injury. Spinal Cord 46: 425-431, 2008

37. Horiuchi T, Kawaguchi M, Kurita N, Inoue S, Nakamura M, Konishi $\mathrm{N}$ and Furuya $\mathrm{H}$ : The long-term effects of mild to moderate hypothermia on gray and white matter injury after spinal cord ischemia in rats. Anesth Analg 109: 559-566, 2009.

38. Levi AD, Green BA, Wang MY, Dietrich WD, Brindle T, Vanni S, Casella G, Elhammady G and Jagid J: Clinical application of modest hypothermia after spinal cord injury. J Neurotrauma 26 407-415, 2009

39. Ahmad FU, Wang MY and Levi AD: Hypothermia for acute spinal cord injury-a review. World Neurosurg 82: 207-214, 2014.

40. Casas CE, Herrera LP, Prusmack C, Ruenes G, Marcillo A and Guest JD: Effects of epidural hypothermic saline infusion on locomotor outcome and tissue preservation after moderate thoracic spinal cord contusion in rats. J Neurosurg Spine 2: 308-318, 2005

41. Morochovic R, Chudá M, Talánová J, Cibur P, Kitka M and Vanický I: Local transcutaneous cooling of the spinal cord in the rat: Effects on long-term outcomes after compression spinal cord injury. Int J Neurosci 118: 555-568, 2008.

42. Morizane K, Ogata T, Morino T, Horiuchi H, Yamaoka G Hino $\mathrm{M}$ and Miura H: A novel thermoelectric cooling device using Peltier modules for inducing local hypothermia of the spinal cord: The effect of local electrically controlled cooling for the treatment of spinal cord injuries in conscious rats. Neurosci Res 72: 279-282, 2012.

43. Barbosa MO, Cristante AF, Santos GB, Ferreira R, Marcon RM and Barros Filho TE: Neuroprotective effect of epidural hypothermia after spinal cord lesion in rats. Clinics (Sao Paulo) 69: 559-564, 2014

44. Albin MS, White RJ, Locke GS, Massopust LC Jr and Kretchmer HE: Localized spinal cord hypthermia-anesthetic effects and application to spinal cord injury. Anesth Analg 46 8-16, 1967

45. Negrin J Jr: Spinal cord hypothermia in the neurosurgical management of the acute and chronic post-traumatic paraplegic patient. Paraplegia 10: 336-343, 1973.
46. Yashon D, Vise WM, Dewey RC and Hunt WE: Temperature of the spinal cord during local hypothermia in dogs. J Neurosurg 39: 742-745, 1973.

47. Dimar JR, Shields CB, Zhang YP, Burke DA, Raque GH and Glassman SD: The role of directly applied hypothermia in spinal cord injury. Spine (Phila Pa 1976) 25: 2294-2302, 2000

48. Chatzipanteli K, Yanagawa Y, Marcillo AE, Kraydieh S, Yezierski RP and Dietrich WD: Posstraumatic hypothermia reduced polymorphonuclear leukocyte accumulation following spinal cord injury in rats. J Neurotrauma 17: 321-332, 2000.

49. Cappuccino A, Bisson LJ, Carpenter B, Marzo J, Dietrich WD and Cappuccino H: The use of systemic hypothermia for the treatment of an acute cervical spinal cord injury in a professional football player. Spine (Phila Pa 1976) 35: E57-E62, 2010.

50. Levi AD, Casella G, Green BA, Dietrich WD, Vanni S, Jagid J and Wang MY: Clinical outcomes using modest intravascular hypothermia after acute cervical spinal cord injury. Neurosurgery 66: 670-677, 2010.

51. Albin MS, White RJ, Yashon D and Harris LS: Effects of localized cooling on spinal cord trauma. J Trauma 9: 1000-1008, 1969.

52. Black P and Markowitz RS: Experimental spinal cord injury in monkeys: Comparison of steroids and local hypothermia. Surg Forum 22: 409-411, 1971

53. Dididze M, Green BA, Dietrich WD, Vanni S, Wang MY and Levi AD: Systemic hypothermia in acute cervical spinal cord injury: A case-controlled study. Spinal Cord 51: 395-400, 2013.

54. MacLaren R, Gallagher J, Shin J, Varnado S and Nguyen L: Assessment of adverse events and predictors of neurological recovery after therapeutic hypothermia. Ann Pharmacother 48: $17-25,2014$

55. Hansebout RR and Hansebout CR: Local cooling for traumatic spinal cord injury: Outcomes in 20 patients and review of the literature. J Neurosurg Spine 20: 550-561, 2014

56. Navarro R, Juhas S, Keshavarzi S, Juhasova J, Motlik J, Johe K Marsala S, Scadeng M, Lazar P, Tomori Z, et al: Chronic spinal compression model in minipigs: A systematic behavioral, qualitative, and quantitative neuropathological study. J Neurotrauma 29: 499-513, 2012.

57. Gedrova S, Galik J, Marsala M, Zavodska M, Pavel J, Sulla I, Gajdos M, Lukac I, Kafka J, Ledecky V, et al: Neuroprotective effect of local hypothermia in a computer-controlled compression model in minipig: Correlation of tissue sparing along the rostro-caudal axis with neurological outcome. Exp Ther Med 15: 254-270, 2018.

58. Sulla I, Boldizar M, Racekova E and Balik V: Experience with a thoracic laminectomy in minipigs. Folia Veterinaria 56: 35-39, 2012.

59. Lim SN, Gladman SJ, Dyall SC, Patel U, Virani N, Kang JX Priestley JV and Michael-Titus AT: Transgenic mice with high endogenous omega- 3 fatty acids are protected from spinal cord injury. Neurobiol Dis 51: 104-112. 2013.

60. Tator $\mathrm{CH}$ and Fehlings MG: Review of the secondary injury theory of acute spinal cord trauma with emphasis on vascular mechanisms. J Neurosurg 75: 15-26, 1991.

61. Rosenfeld JF, Vaccaro AR, Albert TJ, Klein GR and Cotler JM: The benefits of early decompression in cervical spinal cord injury. Am J Orthop (Belle Mead NJ) 27: 23-28, 1998.

62. Fehlings MG and Perrin RG: The timing of surgical intervention in the treatment of spinal cord injury: A systematic review of recent clinical evidence. Spine (Phila Pa 1976) 31 (11 Suppl): S28-S36, 2006

63. Smith JS, Anderson R, Pham T, Bhatia N, Steward O and Gupta R: Role of early surgical decompression of the intradural space after cervical spinal cord injury in an animal model. J Bone Joint Surg Am 92: 1206-1214, 2010.

64. Perkins PG and Deane RH: Long-term follow-up of six patients with acute spinal injury following dural decompression. Injury 19: 397-401, 1988.

65. Phang I, Werndle MC, Saadoun S, Varsos G, Czosnyka M, Zoumprouli A and Papadopoulos MC: Expansion duroplasty improves intraspinal pressure, spinal cord perfusion pressure, and vascular pressure reactivity index in patients with traumatic spinal cord injury: Injured spinal cord pressure evaluation study. J Neurotrauma 32: 865-874, 2015.

66. Kong CY, Hosseini AM, Belanger LM, Ronco JJ, Paquette SJ, Boyd MC, Dea N, Street J, Fisher CG, Dvorak MF and Kwon BK: A prospective evaluation of hemodynamic management in acute spinal cord injury patients. Spinal Cord 51: 466-471, 2013. 
67. Iannotti C, Zhang YP, Shields LB, Han Y, Burke DA, Xu XM and Shields CB: Dural repair reduces connective tissue scar invasion and cystic cavity formation after acute spinal cord laceration injury in adult rats. J Neurotrauma 23: 853-865, 2006.

68. Desai A, Ball PA, Bekelis K, Lurie J, Mirza SK, Tosteson TD and Weinstein JN: SPORT: Does incidental durotomy affect long-term outcomes in cases of spinal stenosis? Neurosurgery 69: 38-44, 2011.

69. Jones CF, Cripton PA and Kwon BK: Gross morphological changes of the spinal cord immediately after surgical decompression in a large animal model of traumatic spinal cord injury. Spine (Phila Pa 1976) 37: E890-E899, 2012.

70. Jones CF, Newell RS, Lee JH, Cripton PA and Kwon BK: The pressure distribution of cerebrospinal fluid responds to residual compression and decompression in an animal model of acute spinal cord injury. Spine (Phila Pa 1976) 37: E1422-E1431, 2012

71. Schumacher PA, Siman RG and Fehlings MG: Pretreatment with calpain inhibitor CEP-4143 inhibits calpain I activation and cytoskeletal degradation, improves neurological function, and enhances axonal survival after traumatic spinal cord injury. J Neurochem 74: E1646-E1655, 2000.

72. Nishida F, Sisti MS,ZZanuzzi CN, Barbeito CG and Portiansky EL: Neurons of the rat cervical spinal cord express vimentin and neurofilament after intraparenchymal injection of kainic acid. Neurosci Lett 643: 103-110, 2017.

73. Lépinoux-Chambaud $\mathrm{C}$ and Eyer J: Review on intermediate filaments of the nervous system and their pathological alterations Histochem Cell Biol 140: 13-22, 2013.

74. Wang $\mathrm{H}$, Wu M, Zhan C, Ma E, Yang M, Yang $X$ and $\mathrm{Li}$ Y: Neurofilament proteins in axonal regeneration and neurodegenerative diseases. Neural Regen Res 7: 620-626, 2012.

75. Greig A, Donevan SD, Mujtaba TJ, Parks TN and Rao MS: Characterization of the AMPA-activated receptors present on motoneurons. J Neurochem 74: 179-191, 2000.

76. Vandenberghe W, Ihle EC, Patneau DK, Robberecht W and Brorson JR: AMPA receptor current density, not desensitization, predicts selective motoneuron vulnerability. J Neurosci 20 7158-7166, 2000

77. Van Den Bosch L and Robberecht W: Different receptors mediate motor neuron death induced by short and long exposures to excitotoxicity. Brain Res Bull 53: 383-388, 2000.

78. Lukáčová N, Kisucká A, Pavel J, Hricová L, Kucharíková A Gálik J, Maršala M, Langfort J and Chalimoniuk M: Spinal cord transection modifies neuronal nitric oxide synthase expression in medullar reticular nuclei and in the spinal cord and increases parvalbumin immunopositivity in motoneurons below the site of injury in experimental rabbits. Acta Histochem 114: 518-524, 2012 .
79. Gillinov AM, Redmond JM, Zehr KJ, Troncoso JC, Arroyo S, Lesser RP, Lee AW, Stuart RS, Reitz BA and Baumgartner WA: Superior cerebral protection with profound hypothermia during circulatory arrest. Ann Thorac Surg 55: 1432-1439, 1993.

80. Mezrow CK, Midulla PS, Sadeghi AM, Gandsas A, Wang W, Dapunt OE, Zappulla R and Griepp RB: Evaluation of cerebral metabolism and quantitative electroencephalography after hypothermic circulatory arrest and low-flow cardiopulmonary bypass at different temperatures. J Thorac Cardiovasc Surg 107: 1006-1019, 1994.

81. Lima B, Williams JB, Bhattacharya SD, Shah AA, Andersen N, Gaca JG and Hughes GC: Results of proximal arch replacement using deep hypothermia for circulatory arrest: Is moderate hypothermia really justifiable? Am Surg 77: 1438-1444, 2011.

82. Vanický I, Marsala M, Gálik J and Marsala J: Epidural perfusion cooling protection against protracted spinal cord ischemia in rabbits. J Neurosurg 79: 736-741, 1993.

83. Lucas JH, Wang GF and Gross GW: NMDA antagonists prevent hypothermic injury and death of mammalian spinal neurons. J Neurotrauma 7: 229-236, 1990.

84. Romero-Sierra C, Hansebout R, Sierhuis A and Lewin M: A new method for localized spinal cord cooling. Med Biol Enf 12: 188-193, 1974.

85. Marsala M, Vanicky I, Galik J, Radonak J, Kundrat I and Marsala J: Panmyelic epidural cooling protects against ischemic spinal cord damage. J Surg Res 55: 21-31, 1993.

86. Marsala M, Galik J, Ishikawa T and Yaksh TL: Technique of selective spinal cord cooling in rat: Methodology and application. J Neurosci Methods 74: 97-106, 1997.

87. Teh DBL, Chua SM, Prasad A, Kakkos I, Jiang W, Yue M, Liu X and All AH: Neuroprotective assessment of prolonged local hypothermia post contusive spinal cord injury in rodent model. Spine J 18: 507-514, 2018.

88. Camara AK, Riess ML, Kevin LG, Novalija E and Stowe DF: Hypothermia augments reactive oxygen species detected in the guinea pig isolated perfused heart. Am J Physiol Heart Circ Physiol 286: H1289-H1299, 2004.

This work is licensed under a Creative Commons Attribution-NonCommercial-NoDerivatives 4.0 International (CC BY-NC-ND 4.0) License. 